\title{
Validation, comparison, and integration of GOCI, AHI, MODIS, MISR, and VIIRS aerosol optical depth over East Asia during the 2016 KORUS-AQ campaign
}

\author{
Myungje Choi ${ }^{1,2}$, Hyunkwang Lim ${ }^{1}$, Jhoon Kim ${ }^{1}$, Seoyoung Lee ${ }^{1}$, Thomas F. Eck ${ }^{3,4}$, Brent N. Holben ${ }^{4}$, \\ Michael J. Garay ${ }^{2}$, Edward J. Hyer ${ }^{5}$, Pablo E. Saide ${ }^{6,7}$, and Hongqing Liu ${ }^{8,9}$ \\ ${ }^{1}$ Department of Atmospheric Sciences, Yonsei University, Seoul, Republic of Korea \\ ${ }^{2}$ Jet Propulsion Laboratory, California Institute of Technology, Pasadena, CA, USA \\ ${ }^{3}$ Universities Space Research Association, Columbia, MD, USA \\ ${ }^{4}$ NASA Goddard Space Flight Center, Greenbelt, MD, USA \\ ${ }^{5}$ Marine Meteorology Division, Naval Research Laboratory, Monterey, CA, USA \\ ${ }^{6}$ Department of Atmospheric and Oceanic Sciences, University of California - Los Angeles, Los Angeles, CA, USA \\ ${ }^{7}$ Institute of the Environment and Sustainability, University of California - Los Angeles, Los Angeles, CA, USA \\ ${ }^{8}$ National Oceanic and Atmospheric Administration, National Environmental Satellite, Data, and Information Service, \\ Center for Satellite Applications and Research, College Park, MD, USA \\ ${ }^{9}$ I. M. Systems Group, Inc., College Park, MD, USA
}

Correspondence: Jhoon Kim (jkim2@yonsei.ac.kr) and Myungje Choi (myungje.choi@jpl.nasa.gov)

Received: 7 February 2019 - Discussion started: 18 March 2019

Revised: 23 June 2019 - Accepted: 5 July 2019 - Published: 30 August 2019

\begin{abstract}
Recently launched multichannel geostationary Earth orbit (GEO) satellite sensors, such as the Geostationary Ocean Color Imager (GOCI) and the Advanced Himawari Imager (AHI), provide aerosol products over East Asia with high accuracy, which enables the monitoring of rapid diurnal variations and the transboundary transport of aerosols. Most aerosol studies to date have used low Earth orbit (LEO) satellite sensors, such as the Moderate Resolution Imaging Spectroradiometer (MODIS) and the Multiangle Imaging Spectroradiometer (MISR), with a maximum of one or two overpass daylight times per day from midlatitudes to low latitudes. Thus, the demand for new GEO observations with high temporal resolution and improved accuracy has been significant. In this study the latest versions of aerosol optical depth (AOD) products from three LEO sensors - MODIS (Dark Target, Deep Blue, and MAIAC), MISR, and the Visible/Infrared Imager Radiometer Suite (VIIRS), along with two GEO sensors (GOCI and AHI), are validated, compared, and integrated for a period during the Korea-United States Air Quality Study (KORUS-AQ) field campaign from 1 May to 12 June 2016 over East Asia. The AOD products analyzed here generally have high accuracy
\end{abstract}

with high $R(0.84-0.93)$ and low RMSE (0.12-0.17), but their error characteristics differ according to the use of several different surface-reflectance estimation methods. Highaccuracy near-real-time GOCI and AHI measurements facilitate the detection of rapid AOD changes, such as smoke aerosol transport from Russia to Japan on 18-21 May 2016, heavy pollution transport from China to the Korean Peninsula on 25 May 2016, and local emission transport from the Seoul Metropolitan Area to the Yellow Sea in South Korea on 5 June 2016. These high-temporal-resolution GEO measurements result in more representative daily AOD values and make a greater contribution to a combined daily AOD product assembled by median value selection with a $0.5^{\circ} \times 0.5^{\circ}$ grid resolution. The combined AOD is spatially continuous and has a greater number of pixels with high accuracy (fraction within expected error range of 0.61) than individual products. This study characterizes aerosol measurements from LEO and GEO satellites currently in operation over East Asia, and the results presented here can be used to evaluate satellite measurement bias and air quality models. 


\section{Introduction}

Atmospheric aerosol particles are composed of solid and liquid matter and have diameters of a few nanometers up to several micrometers and lifetimes from a single day to tens of days. Aerosol particles affect the atmospheric radiation balance by scattering and absorbing incident top-ofatmosphere (TOA) sunlight and light scattered from the surface, as well as by interacting with clouds (e.g., by changing cloud distributions, optical properties, and precipitation by acting as cloud condensation nuclei) with global climate effects (IPCC, 2013). Global net radiative cooling or heating is determined partially by interactions for which the level of understanding is still low and varies significantly with geographic region. Additionally, ambient particulate matter (PM) at the ground level adversely affects human health through pulmonary and respiratory transport, resulting in heart disease, stroke, and lung cancer (Gao et al., 2015; Lim et al., 2012). Many developing countries in East Asia have both large anthropogenic emission sources and natural aerosol sources, such as the Taklamakan and Gobi deserts and wildfire regions. For this reason, East Asia currently has one of the most heavily polluted atmospheres in the world (S. W. Kim et al., 2007; Mehta et al., 2016; Yoon et al., 2014; Zhao et al., 2017).

Aerosol measurements are routinely conducted at diverse scales by laboratory experiments, in situ measurements, and remote sensing, and from various platforms including ground-based, airborne, shipborne, and satellite sensors. Accurate microphysical and chemical properties of aerosols can be obtained from laboratory experiments or groundbased and airborne measurements, but their spatial coverage is limited. Satellite-based remote-sensing measurements provide aerosol optical properties, including aerosol optical depth (AOD), over much broader areas. Currently operating low Earth orbit (LEO) satellite sensors, such as the Moderate Resolution Imaging Spectroradiometer (MODIS), the Multi-angle Imaging Spectroradiometer (MISR), and the Visible/Infrared Imager Radiometer Suite (VIIRS), provide global aerosol information but at a temporal resolution that is limited to once per day at least and, typically, to once every 2-3 d due to cloud cover (Garay et al., 2017; Hsu et al., 2013; Jackson et al., 2013; Levy et al., 2013). Most satellite-based aerosol retrieval techniques and algorithms have been developed for these LEO sensors (Diner et al., 1998; Higurashi and Nakajima, 1999; Hsu et al., 2004; Kaufman et al., 1997; J. Kim et al., 2007; Remer et al., 2005; Torres et al., 1998). To overcome temporal resolution limitations, there were several attempts to retrieve AOD using first-generation meteorological geostationary satellites such as the Geostationary Operational Environmental Satellite (GOES), the Geostationary Meteorological Satellite (GMS), and the Multifunction Transport Satellite (MTSAT), but they showed worse accuracy than those of LEO sensors due to the wider and fewer visible channels with coarser spatial resolution, which make it difficult to distinguish aerosol types (Kim et al., 2008; Knapp et al., 2002; Urm and Sohn, 2005; Wang et al., 2003; Yoon et al., 2007). As the specifications of recently launched geostationary Earth orbit (GEO) sensors, such as the Geostationary Ocean Color Imager (GOCI) and the Advanced Himawari Imager (AHI) over East Asia and the Advanced Baseline Imager (ABI) over the United States, are approaching those of current LEO sensors, aerosol optical properties can be retrieved with an accuracy as high as that of LEO sensors, and at much higher temporal resolutions, from a few minutes to an hour during daylight hours (Chen et al., 2018; Choi et al., 2016, 2018; Daisaku, 2016; Kikuchi et al., 2018; Laszlo and Liu, 2016; Lee et al., 2010; Lim et al., 2018; Zhang et al., 2018). This breakthrough in temporal resolution of GEO aerosol data enables us to monitor highly variable aerosol conditions and improve air quality forecasting, particularly for PM, with data assimilation (Jeon et al., 2016; Lee et al., 2016; Pang et al., 2018; Park et al., 2014; Saide et al., 2014) or machine learning (Park et al., 2019). To improve air quality model accuracy through satellite AOD retrieval, the satellite AOD should have broader coverage, high spatiotemporal resolution, and high accuracy. Most AOD data assimilation systems have been developed by using LEO satellite products such as MODIS because they have global coverage and high accuracy through the continuous retrieval algorithm improvement. The GEO satellite can provide more frequent $\mathrm{AOD}$, but its spatial coverage can be limited to a specific area, especially in the case of GOCI. The period of AOD retrieval algorithm development and investigation using GEO is relatively shorter than LEO. Also, LEO sensors generally have more suitable channels with a high resolution and advanced measurement characteristics such as multi-angle and/or polarization for aerosol retrievals, which could result in higher accuracy of AOD from LEO than GEO generally (Jiang et al., 2019). Therefore, both accuracy and spatiotemporal coverage can be obtained simultaneously by using combined GEO and LEO AODs. For these reasons, the demand for GEO aerosol measurements is high.

Satellite aerosol retrieval algorithms have been improved toward higher spatial resolution (e.g., 5-10 km or finer) and higher temporal resolution (e.g., from daily to hourly and few minutes resolution) with higher accuracy (e.g., AOD uncertainty less than 0.03 or $10 \%$ ) to fulfill the requirement for an understanding of long-term climatological changes (GCOS, 2016).

Several field campaigns have been performed over East Asia to investigate aerosol chemical, microphysical, and optical properties based on in situ and remote-sensing measurements. These include the Transport and Chemical Evolution over the Pacific (TRACE-P) aircraft campaign in 2001 (Jacob et al., 2003), the Atmospheric Brown Cloud-East Asia Regional Experiment (ABC-EARES) in 2005 (Nakajima et al., 2007), the Distributed Regional Aerosol Gridded Observation Networks (DRAGON)-Asia campaign in 2012 (Holben et al., 2018), and the Megacity Air Pollution Studies (MAPS) 
in 2015 (Kim et al., 2018). Aerosol retrieval algorithms have been developed, improved, and validated using the extensive measurement datasets obtained from these field campaign studies (Garay et al., 2017; Jeong et al., 2016; S. W. Kim et al., 2007, 2016; Lee et al., 2018; Xiao et al., 2016).

The Korea-United States Air Quality Study (KORUSAQ; https://www-air.larc.nasa.gov/missions/korus-aq/, last access: 29 July 2019) was performed over the Korean Peninsula from 1 May to 12 June 2016 under the leadership of Korea's National Institute of Environmental Research (NIER) and the United States National Aeronautics and Space Administration (NASA). Compared to previous field campaigns, the KORUS-AQ campaign consists of more extensive measurement platforms from ground sites, aircrafts, ship, and satellites, especially focused on geostationary satellites. The GOCI data were made available in near-real-time for satellite aerosol measurements during the campaign and they are also an optimized test bed of future geostationary air quality satellites of GEMS (Geostationary Environment Monitoring Spectrometer; Kim et al., 2019), TEMPO (Tropospheric Emissions: Monitoring of Pollution; Zoogman et al., 2017), and Sentinel-4 (Ingmann et al., 2012). During the campaign, GOCI aerosol optical properties were retrieved and provided in near real time to support air quality forecasting, determination of the flight plan for aircraft measurements to detect heavy pollution plumes, and data assimilation using near-real-time chemical transport model simulations (Choi et al., 2018; Saide et al., 2014). Also, the GOCI AOD was used to evaluate a Japanese non-hydrostatic icosahedral atmospheric model (NICAM) AOD and to analyze diurnal variation in AOD and $\mathrm{PM}_{2.5}$ over the Korean Peninsula (Goto et al., 2019; Lennartson et al., 2018). Since most aerosol analysis and application studies using satellites have still been demonstrated by using LEO satellite products such as MODIS, new aerosol products from GEO should be verified in terms of quality and spatiotemporal coverages through comparison with LEO satellite measurement. Therefore, this study aims to validate multiple GEO and LEO satellite AOD products using ground-based AERONET, compare specific aerosol event cases to understand different characteristics of GEO and LEO AODs, and integrate them for representative AOD distribution.

Here, in addition to the GOCI AOD dataset, the latest versions of AOD datasets from LEO sensors (MODIS, MISR, and VIIRS) and another GEO sensor (AHI) are validated, compared, and integrated for the period of the field campaign. The latest version of the Aerosol Robotic Network (AERONET) ground-based sun photometer dataset (version 3 ) over East Asia is used as a reference for the campaign period (Eck et al., 2018; Giles et al., 2019). Characteristics of the various AOD products are analyzed for specific transport cases with a high temporal resolution at the daily scale over the campaign period.

The remainder of this paper is organized as follows. In Sect. 2, satellite and ground-based remote-sensing data used in this study are summarized. In Sect. 3, the various AOD products are validated and compared using ground-based AERONET observations separately over ocean and land. The specific aerosol loading cases during the campaign are analyzed in Sect. 4. In Sect. 5, daily representative AOD is generated on a common spatial grid for each product and used to calculate the mean AOD distribution during the campaign. The daily AOD integration is tested using multiple AOD products at the daily scale. Finally, a discussion and conclusions are presented in Sect. 6.

\section{Satellite and ground-based AERONET aerosol data}

\subsection{GOCI Yonsei aerosol product}

The GOCI is a unique ocean color sensor in GEO $\left(128.2^{\circ} \mathrm{E}\right)$ on board the Korean Communication, Ocean, and Meteorological Satellite (COMS) and has been making observations over East Asia since 2010. It covers a $2500 \mathrm{~km} \times 2500 \mathrm{~km}$ area centered over the Korean Peninsula, such that the eastern part of China and Japan are also covered at a $500 \mathrm{~m} \times 500 \mathrm{~m}$ spatial resolution and $1 \mathrm{~h}$ temporal resolution from 09:30 to 16:30 local time (LT; coordinated universal time, UTC + 9; with a total of eight measurements during daylight hours). Aerosol optical depth at $550 \mathrm{~nm}$ is retrieved using the GOCI Yonsei aerosol retrieval (YAER) algorithm at a $6 \mathrm{~km} \times 6 \mathrm{~km}$ spatial resolution after masking pixels affected by clouds or sun glint and aggregating the remaining pixels to provide aerosol signals at the resolution of the reflectance measurements. Land surface reflectance is obtained using the minimum reflectance technique for each month and hour of Rayleigh-corrected reflectance measurements (Herman and Celarier, 1997; Hsu et al., 2004; Koelemeijer et al., 2003). Ocean surface reflectance is based on the Cox-Munk ocean bidirectional reflectance distribution function (BRDF) (Cox and Munk, 1954). Details of the aerosol retrieval algorithm and the improvement and validation results for March 2011 to February 2017 are presented by Choi et al. (2016, 2018).

According to Choi et al. (2018), the GOCI YAER version 2 AOD shows increased errors when the geometrical cloud fraction within AOD pixel increases (particularly near cloud edges) and the remaining cloud contamination was largely due to the absence of infrared (IR) measurement in GOCI. Thus, in this study, additional cloud masking is applied to the GOCI cloud-masking procedure, using Himawari-8 IR data. The IR cloud masking processes in the AHI YAER algorithm is summarized as in Table 2, which are based on several previous studies (Iwabuchi et al., 2014; Kim et al., 2014). It consists of four tests using the brightness temperature (BT) difference (BTD) of a different IR channel pair to detect high-level cloud, low-level cloud, and cirrus cloud, which are difficult to detect or classify using only visible channels of GOCI. The AHI IR cloud masking information has $2 \mathrm{~km}$ spatial resolution (at the Equator) every $10 \mathrm{~min}$ for 


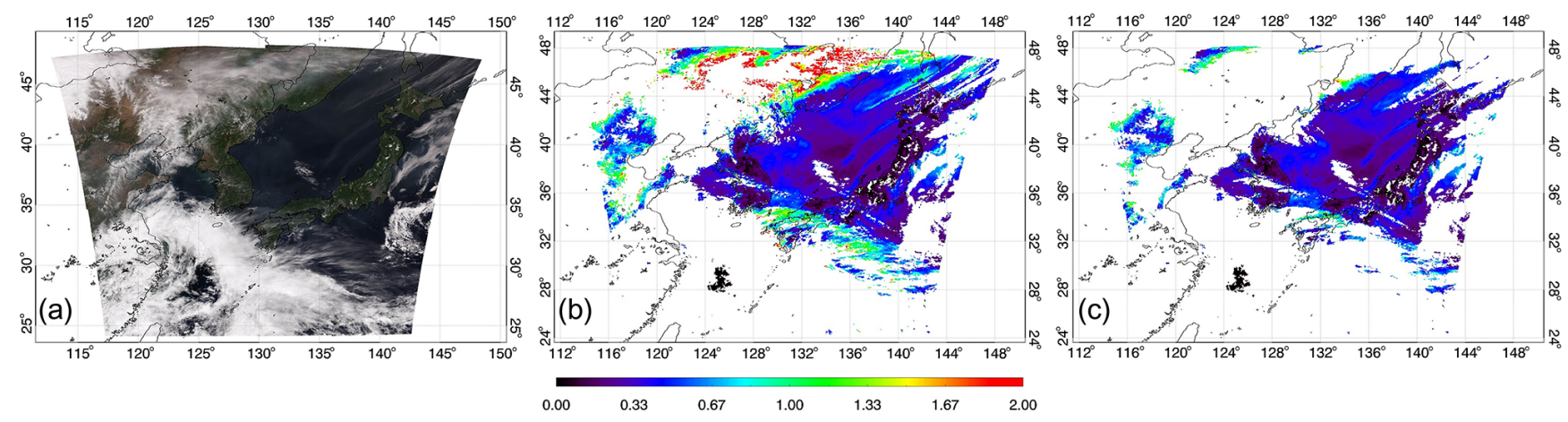

Figure 1. The case of 22 May 2016, 13:30 LT: (a) true color image, (b) GOCI YAER V2 AOD without additional cloud masking, and (c) GOCI YAER V2 AOD with additional cloud masking using AHI IR channels.
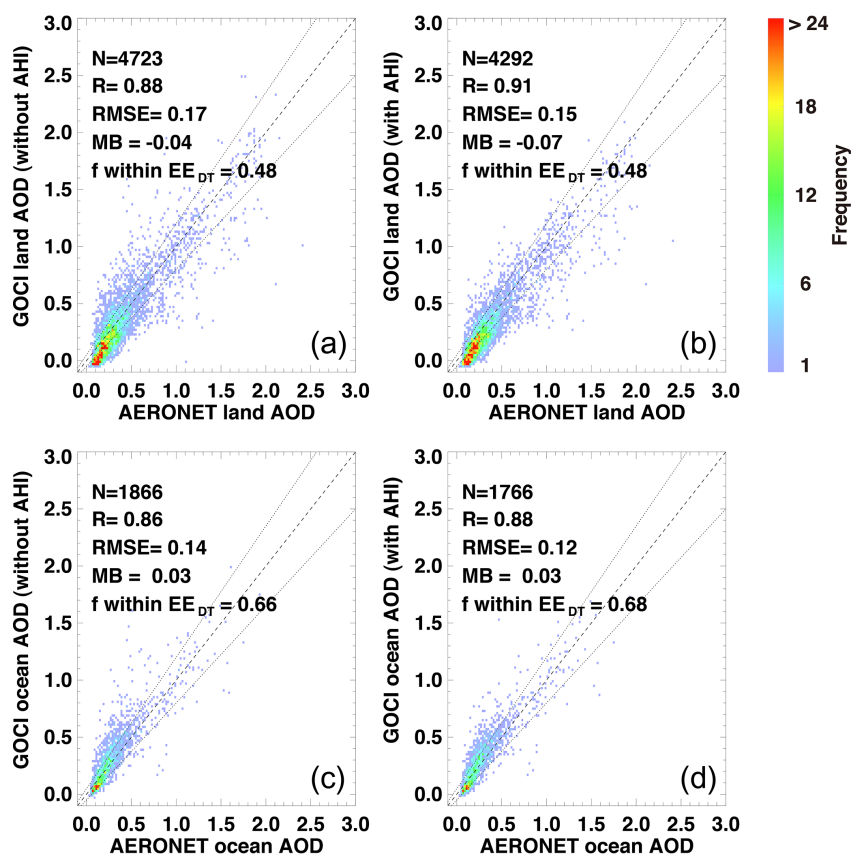

Figure 2. Comparison of AERONET AOD and (a) GOCI land AOD without additional cloud masking, (b) GOCI land AOD with additional cloud masking, (a) GOCI ocean AOD without additional cloud masking, and (b) GOCI ocean AOD with additional cloud masking using AHI IR channels. Black lines indicate zero difference and the $\mathrm{EE}_{\mathrm{DT}}$ range $\pm\left(0.05+0.15 \times \mathrm{AOD}_{\mathrm{AERONET}}\right)$.

the full-disk area, thus the co-location processing is required to match with GOCI of $500 \mathrm{~m}$ spatial resolution and $1 \mathrm{~h}$ temporal resolution. The spatially closest AHI IR pixel to each GOCI pixel is co-located. The GOCI observation takes from 15 to $45 \mathrm{~min}$ of each hour, thus the pixels are flagged as cloud if at least one of 10, 20,30,40, and 50 min of each hour of AHI measurements determines the pixels as cloud. Then, the co-located AHI IR cloud information is applied to the GOCI at $500 \mathrm{~m}$ spatial resolution between the original cloud masking step and the pixel aggregation step to $6 \mathrm{~km}$. Details of the full AHI IR cloud masking procedure for aerosol retrieval are described by Lim et al. (2018). On 22 May 2016, thin cloud was detected over Manchuria $\left(44-48^{\circ} \mathrm{N}, 125-140^{\circ} \mathrm{E}\right)$ and southern ocean of Japan $\left(30-34^{\circ} \mathrm{N}, 128-140^{\circ} \mathrm{E}\right)$ from the GOCI true color image (Fig. 1a). The original cloud masking of the GOCI algorithm could not classify pixels as cloudy near cloud edge and result in high AOD close to 2 (Fig. 1b). Those pixels are filtered out well when AHI IR cloud masking was applied to the GOCI algorithm (Fig. 1c). The GOCI YAER V2 AOD before and after additional AHI IR cloud masking was also compared to the ground-based AERONET in Sect. 3.

\subsection{AHI Yonsei aerosol product}

The AHI, on board the Himawari-8 and Himawari-9 satellites, is part of a new generation of meteorological satellite sensors. Compared with previous meteorological sensors, such as the Japanese Advanced Meteorological Imager (JAMI) on board the Japanese Multifunction Transport Satellite-1R (MTSAT-1R, also referred to as Himawari-6) or the Meteorological Imager (MI) on board the Korean COMS satellite, the AHI has more channels (16) including three visible channels $(0.47,0.51$, and $0.64 \mu \mathrm{m})$ with higher spatial resolution $(0.5$ to $2.0 \mathrm{~km})$. More visible channels with a narrow bandwidth of AHI, compared to the one broad visible channel of JAMI and MI, enable aerosol type classification and improves aerosol retrieval accuracy. The primary advantage of AHI is the high temporal resolution: 2.5 min over Japan and $10 \mathrm{~min}$ over the full-disk area centered at $140.7^{\circ} \mathrm{E}$. The full-disk observation area covers East Asia (eastern India, Southeast Asia, the Korean Peninsula, Japan, most of China, and parts of Russia and Oceania). The AHI Yonsei aerosol retrieval algorithm applies two distinct schemes (Lim et al., 2018). The first scheme is based on the Dark Target approach over land using a $1.6 \mu \mathrm{m}$ shortwave infrared (SWIR) channel and the Cox-Munk ocean BRDF model with chlorophyll $a$ to simulate the water-leaving radiance over the ocean, referred to as the estimated surface reflectance (ESR) method. 
Official AHI JAXA chlorophyll $a$ concentration data are spatiotemporally interpolated to the AHI Yonsei aerosol product pixels and used to calculate the ocean surface reflectance. The second scheme is based on the minimum surface reflectance over land and ocean, referred to as the minimum reflectance method (MRM). The AHI YAER algorithm provides two versions of $550 \mathrm{~nm}$ AOD with a $6 \mathrm{~km} \times 6 \mathrm{~km}$ spatial resolution. Details of the AHI YAER algorithm are presented by Lim et al. (2018). The full-disk area is measured by AHI in 10 segments from north to south. The second and third segments approximately cover the area $20-48^{\circ} \mathrm{N}$ and are used to retrieve AOD using the YAER algorithm in this study.

\subsection{MODIS Dark Target aerosol product}

MODIS is one of the most widely used instruments for global aerosol measurements. It has been in operation on board NASA Terra (10:30LT descending) satellite since 1999 and the Aqua (13:30 LT ascending) satellite since 2002. In general, MODIS measurements employ single-angle viewing, multiple channels (36 channels), high spatial resolution ( 0.25 to $1.00 \mathrm{~km}$ according to channel), and a wide swath $(2330 \mathrm{~km})$ enabling daily global coverage for shortwave channels. The MODIS Dark Target (DT) aerosol retrieval algorithm uses the broader-bandwidth MODIS channels $(>20 \mathrm{~nm})$ in the visible to SWIR range. The DT algorithm assumes that land surface reflectance in the visible range has a linear relationship with SWIR $(2.1 \mu \mathrm{m})$ surface reflectance, where the atmospheric signal is low (Kaufman et al., 1997), which varies according to the Normalized Difference Vegetation Index (NDVI). This approach is applied to dark land surfaces, e.g., vegetated areas. Ocean surface reflectance is based on Fresnel reflectance with the CoxMunk assumption. The MODIS DT algorithm uses NCEP wind-speed analysis data as input and calculates ocean surface reflectance according to geometry and wind speed. The MODIS DT AOD at $550 \mathrm{~nm}$ is provided at $10 \mathrm{~km} \times 10 \mathrm{~km}$ and $3 \mathrm{~km} \times 3 \mathrm{~km}$ spatial resolution at nadir after pixel aggregation at the spatial resolution of the reflectance data. In this study, the latest version "Collection 6.1 (C6.1)" data of only the best quality ("Quality Assurance Flag 3") land and ocean $550 \mathrm{~nm}$ AOD for both resolutions are used (Gupta et al., 2016; Levy et al., 2013; Munchak et al., 2013).

\subsection{MODIS Deep Blue aerosol product}

The MODIS Deep Blue (DB) aerosol algorithm uses ocean color channels and IR channels to retrieve aerosol optical properties over bright land surfaces. Using the enhanced DB algorithm, MODIS DB AOD is retrieved over arid and semiarid surfaces; natural vegetation areas; and urban, built-up, and transitional regions using several surface-reflectance calculations. These calculations use a pre-calculated surface reflectance database with the minimum reflectance technique, a DT-like approach, and a hybrid method over arid and semiarid surfaces, vegetation, and urban, built-up, and transition surfaces. The MODIS DB algorithm calculates AOD for each of the original level 1B (L1B) $1 \mathrm{~km}$ pixels, and aggregates and averages retrieved AOD pixels to $10 \mathrm{~km} \times 10 \mathrm{~km}$ resolution at nadir after appropriate masking procedures that differ from those in the MODIS DT and GOCI YAER algorithms. The latest version C6.1 MODIS DB land $550 \mathrm{~nm}$ AOD of only the best quality is also used in this study (Hsu et al., 2013; Sayer et al., 2013, 2019).

\subsection{MODIS MAIAC aerosol product}

The MODIS multiangle implementation of atmospheric correction (MAIAC) aerosol algorithm performs aerosol retrievals and atmospheric correction over both dark vegetated surfaces and bright desert land surfaces (Lyapustin et al., 2011a, b). Compared to each scene and pixel-based approach of MODIS DT and DB algorithm, the MAIAC algorithm has a time series analysis and image-based processing. Maximum $16 \mathrm{~d}$ data that have multi-viewing angle are used to obtain surface bidirectional reflectance distribution function (BRDF) characteristics providing three parameters of the Ross-thick Li-sparse BRDF model. Recent MODIS Collection 6 MAIAC aerosol algorithm was improved in terms of higher spatial resolution of surface characterization from 25 to $1 \mathrm{~km}$, cloud detection, aerosol model, optimization of LUT-based radiative transfer calculation, and others (Lyapustin et al., 2018). Also, an over-water retrieval process based on Fresnel reflectance model with the Cox-Munk assumption was added to provide ocean AOD. The MAIAC algorithm uses eight different aerosol models and the same channels as the MODIS DT algorithm for AOD inversion. The latest version C6 MODIS MAIAC $550 \mathrm{~nm}$ AOD pixels with the "best quality" are used in this study.

\subsection{VIIRS EPS aerosol product}

The VIIRS is a sensor on board the Suomi-NPP satellite, which was launched in October 2011. The general characteristics of VIIRS are similar to those of MODIS, and include single-angle viewing, multiple channels (22 channels), high spatial resolution $(375-750 \mathrm{~m})$, and a wide swath $(3040 \mathrm{~km})$ that results in no gaps between adjacent swaths near the Equator. Recent VIIRS aerosol products provided by NOAA were updated from the previous Environmental Data Record (EDR) and the Intermediate Product (IP) to the new Enterprise Processing System (EPS) product. The previous VIIRS EDR and IP aerosol retrieval algorithm was similar to the DT algorithm in terms of the coupling of land surface reflectance in the visible range using the SWIR channel $(2.25 \mu \mathrm{m})$, ocean surface reflectance that considers wind speed and direction using the Cox-Munk model with Fresnel reflectance, and a combination of fine- and coarse-aerosol models (Jackson et al., 2013 and Huang et al., 2016). The new VIIRS EPS 
aerosol algorithm is able to retrieve AOD over both dark and bright areas using the surface reflectance ratio method (Zhang et al., 2016). The global surface reflectance ratio was obtained as $0.1^{\circ} \times 0.1^{\circ}$ spatial resolution using 2 years of VIIRS TOA reflectance. The EPS aerosol product is calculated at a $0.75 \mathrm{~km} \times 0.75 \mathrm{~km}$ spatial resolution at nadir. In this study, the VIIRS EPS $550 \mathrm{~nm}$ AOD is used.

\subsection{MISR aerosol product}

The MISR is one of the sensors on board the Terra satellite along with MODIS. Unique characteristics of MISR include multichannel (four wavelengths, centered at 446, 558, 672 , and $866 \mathrm{~nm}$ ) and multi-angle measurements (nine cameras; nadir, $\pm 26.1, \pm 45.6, \pm 60.0$, and $\pm 70.5^{\circ}$ ), which enable better detection of aerosol particle shapes and a distinction between atmospheric and surface signals through calculation of surface bidirectional reflectance factors (BRF). The MISR spatial resolutions at nadir and off-nadir are $250 \mathrm{~m}$ $\times 250 \mathrm{~m}$ and $275 \mathrm{~m} \times 275 \mathrm{~m}$, respectively, and the operational MISR aerosol retrieval algorithm provides $550 \mathrm{~nm}$ AOD and other optical properties at $17.6 \mathrm{~km} \times 17.6 \mathrm{~km}$ in version 22 and $4.4 \mathrm{~km} \times 4.4 \mathrm{~km}$ in version 23 after pixel masking and aggregation at the spatial resolution of the reflectance data. Targeted surface conditions for aerosol retrieval are dark ocean, dark vegetation, and bright arid land surfaces. A total of 74 aerosol models are put into an ensemble of retrieved AOD in an inversion procedure and uncertainty is obtained at the same time. One advantage of MISR measurements is the absence of non-retrieval areas caused by sun glint effects that are present in nadir-only viewing measurements, such as MODIS. The swath is $\sim 380 \mathrm{~km}$, which is narrower than MODIS, and results in global coverage every $9 \mathrm{~d}$, with repeat coverage between 2 and $9 \mathrm{~d}$ depending on latitude (2-3d near the Korean Peninsula). In this study, version 23 AOD at $550 \mathrm{~nm}$ is used (Garay et al., 2017; Witek et al., 2018).

\subsection{AERONET measurements during the KORUS-AQ campaign}

To evaluate the various satellite AOD products during the 2016 KORUS-AQ campaign (1 May to 12 June 2016), extensive data from ground-based remote-sensing AERONET sun-sky radiometers were collected from total 33 sites over East Asia, including 19 South Korean sites (Holben et al., 1998, 2018). Detailed site information, including locations, is available at the AERONET home page (https://aeronet.gsfc.nasa.gov/ new_web/DRAGON-KORUS-AQ_2016.html, last access: 29 July 2019). AERONET provides high-accuracy measurement of AOD with uncertainty of $\sim 0.01$ in the mid-visible (Eck et al., 1999). The AERONET version 3 level 2.0 AOD at $550 \mathrm{~nm}$ all-points data at a temporal resolution of a few minutes are used (Eck et al., 2018; Giles et al., 2019). To compare satellite and ground-based AERONET
AOD, spatiotemporal co-location is implemented. This study follows the general co-location criteria of Sayer et al. (2014): satellite pixels within a $25 \mathrm{~km}$ radius of each AERONET site are spatially averaged, and AERONET data within a \pm 30 min window around the satellite measurements are temporally averaged. Note that the 10 min interval AHI AOD data are co-located with AERONET AOD within a \pm 5 min temporal window. Because there are only a few AERONET sites surrounded by ocean, AERONET sites located on a coast are used to validate satellite ocean AOD. Also note that a co-located sample is included in the average if at least one measurement is available.

\subsection{SONET measurements during the KORUS-AQ campaign}

The Sun-Sky Radiometer Observation Network (SONET) operated by the Institute of Remote Sensing and Digital Earth, Chinese Academy of Sciences also provides aerosol optical and microphysical data from ground-based CIMEL sun-sky radiometer measurement using their own retrieval algorithm (Li et al., 2018). A total of five SONET sites' data (Harbin, Hefei, Nanjing, Shanghai, and Zhoushan) are used to evaluate satellite land AOD products. The SONET aerosol data and site information during the campaign are available from the AERONET home page.

\section{Validation results}

\subsection{Statistical metrics}

The statistical metrics as used by Sayer et al. (2014) were also applied here for comparison of satellite AOD measurements over land and ocean using AERONET and SONET and are summarized in Tables 3, 4, and 5. Because the distribution of AOD is non-Gaussian and skewed towards low values, AOD evaluation is difficult using simple statistical techniques. Thus, the metrics applied here consist of the number of matched and co-located data points $(N)$, Pearson's linear correlation coefficient $(R)$, the root-mean-square error (RMSE), the mean bias (MB) error, and the fraction within the expected error of MODIS Collection 5 DT land AOD [ $f$ within $\mathrm{EE}_{\mathrm{DT}}$ or $f ; \mathrm{EE}_{\mathrm{DT}}= \pm(0.05+0.15 \times$ AERONET AOD)], as suggested by Levy et al. (2007). The range of $\mathrm{EE}_{\mathrm{DT}}$ consists of upper and bottom linear lines and becomes wider as AOD increases, which reflects increasing AOD uncertainties with AOD in general. Ideally, the ratio within EE corresponds to $1 \sigma$ of the Gaussian distribution data $(\sim 68 \%)$. The range was obtained from the global evaluation of MODIS DT Collection 5 AOD products. Each AOD product has its own expected error enveloped as summarized in Choi et al. (2018), but the $\mathrm{EE}_{\mathrm{DT}}$ was selected to compare different product performance. 
Table 1. Characteristics of multi-sensor aerosol products.

\begin{tabular}{|c|c|c|c|c|c|}
\hline $\begin{array}{l}\text { Sensor/platform } \\
\text { (orbit type) }\end{array}$ & $\begin{array}{l}\text { GOCI/COMS } \\
\text { (GEO) }\end{array}$ & $\begin{array}{l}\text { AHI/Himawari-8 } \\
\text { (GEO) }\end{array}$ & $\begin{array}{l}\text { MODIS/Terra, } \\
\text { Aqua (LEO) }\end{array}$ & $\begin{array}{l}\text { VIIRS/Suomi-NPP } \\
\text { (LEO) }\end{array}$ & MISR/Terra (LEO) \\
\hline $\begin{array}{l}\text { Swath for LEO } \\
\text { or local cover- } \\
\text { age for GEO }\end{array}$ & $\begin{array}{l}2500 \mathrm{~km} \times 2500 \mathrm{~km} \\
\text { area over East Asia } \\
\text { centered at } 36^{\circ} \mathrm{N} \text {, } \\
130^{\circ} \mathrm{E}\end{array}$ & $\begin{array}{l}\text { Full disk centered } \\
\text { at } 140.7^{\circ} \mathrm{E}\end{array}$ & $2330 \mathrm{~km}$ & $3040 \mathrm{~km}$ & $380 \mathrm{~km}$ \\
\hline $\begin{array}{l}\text { Algorithm ver- } \\
\text { sion }\end{array}$ & $\begin{array}{l}\text { Yonsei aerosol re- } \\
\text { trieval version } 2\end{array}$ & $\begin{array}{l}\text { Yonsei aerosol re- } \\
\text { trieval }\end{array}$ & $\begin{array}{l}\text { Dark Target Col- } \\
\text { lection 6.1; Deep } \\
\text { Blue Collection } \\
6.1 \text { (land only); } \\
\text { Multi-Angle Im- } \\
\text { plementation of } \\
\text { Atmospheric Cor- } \\
\text { rection (MAIAC) } \\
\text { Collection } 6\end{array}$ & $\begin{array}{l}\text { Enterprise Process- } \\
\text { ing system (EPS) }\end{array}$ & Version 23 \\
\hline $\begin{array}{l}\text { Measurement } \\
\text { time (local } \\
\text { time) }\end{array}$ & $\begin{array}{l}1 \mathrm{~h} \text { interval from } \\
09: 30 \text { to } 16: 30 \\
\text { (eight times during } \\
\text { daylight in total) }\end{array}$ & $\begin{array}{l}10 \text { min interval } \\
\text { for full-disk mea- } \\
\text { surements (only } \\
\text { 09:00-16:50 in this } \\
\text { study) }\end{array}$ & $\begin{array}{l}\text { 10:30 for Terra, } \\
\text { 13:30 for Aqua }\end{array}$ & $13: 25$ & $10: 30$ \\
\hline $\begin{array}{l}\text { Spatial resolu- } \\
\text { tion of aerosol } \\
\text { products (nadir } \\
\text { point for LEO) }\end{array}$ & $6 \mathrm{~km} \times 6 \mathrm{~km}$ & $6 \mathrm{~km} \times 6 \mathrm{~km}$ & $\begin{array}{l}10 \mathrm{~km} \times 10 \mathrm{~km} \text { and } \\
3 \mathrm{~km} \times 3 \mathrm{~km} \\
\text { for DT; } \\
10 \mathrm{~km} \times 10 \mathrm{~km} \text { for } \\
\mathrm{DB} ; \\
1 \mathrm{~km} \times 1 \mathrm{~km} \\
\text { for MAIAC }\end{array}$ & $0.75 \mathrm{~km} \times 0.75 \mathrm{~km}$ & $4.4 \mathrm{~km} \times 4.4 \mathrm{~km}$ \\
\hline References & $\begin{array}{l}\text { Choi et al. (2018); } \\
\text { Choi et al. (2016) }\end{array}$ & Lim et al. (2018) & $\begin{array}{l}\text { Gupta et al. (2016); } \\
\text { Hsu et al. (2013); } \\
\text { Levy et al. (2018); } \\
\text { Lyapustin et } \\
\text { al. (2018); Sayer et } \\
\text { al. (2013) }\end{array}$ & $\begin{array}{l}\text { Huang et al. (2016); } \\
\text { Jackson } \\
\text { et al. (2013); Zhang } \\
\text { et al. (2016) }\end{array}$ & $\begin{array}{l}\text { Garay et al. (2017); } \\
\text { Witek et al. (2018) }\end{array}$ \\
\hline
\end{tabular}

\subsection{Validation of GOCI AOD without and with additional AHI IR cloud masking}

The results of land AOD show increased $R$ from 0.88 to 0.91 and decreased RMSE from 0.17 to 0.15 , which indicates improvement due to the removal of overestimation points in high AOD of GOCI from the scene analysis. However, underestimation in low AOD due to surface reflectance uncertainty increases negative MB from -0.04 to -0.07 and constant $f$ of 0.48 . The ocean AOD that have a smaller uncertainty of surface reflectance shows improvement in most statistical metrics, increasing $R$ from 0.86 to 0.88 , decreasing RMSE from 0.14 to 0.12 , constant MB of 0.03 , and increasing $f$ from 0.66 to 0.68 . The GOCI-II, which is planned to be launched in 2020, also does not have any IR channels, thus it is essential to adopt additional cloud masking from IR channels of AHI or the Advanced Meteorological Imager (AMI) for GOCI-I and GOCI-II aerosol retrieval to reduce shallow or cirrus clouds contamination. Hereafter, the GOCI V2 YAER AOD with additional IR cloud masking is used as GOCI AOD.

\subsection{Land AOD validation using AERONET and SONET}

Each satellite measures the area within its swath at different times during daylight hours, as listed in Table 1. In contrast to the hourly and $10 \mathrm{~min}$ interval measurements of GOCI and AHI, respectively, the LEO satellites observe East Asia only once per day. The overpass time for Terra is at 10:30 LT and those for Aqua and Suomi-NPP are at 13:30 and 13:25 LT, respectively. When measurement times are similar, $N$ can be determined by swath, spatial resolution, and the quality assurance flag, among other factors. Because of gaps arising from its narrow swath, MISR does not fully cover East Asia in a day. This results in the lowest $N$ being 114 for land AOD 
among LEO sensors. In contrast, the MODIS and VIIRS have wider swaths that cover most of East Asia in a day, resulting in higher $N$ between 800 and 1348 over land. Not surprisingly, GOCI and AHI show higher $N$ than all LEO sensors due their to $1 \mathrm{~h}$ and $10 \mathrm{~min}$ temporal resolution, respectively.

All land AOD products show high $R$ from 0.87 to 0.93 . The RMSE ranges 0.12 (MISR) to 0.22 and 0.23 (MODIS DT 10 and $3 \mathrm{~km}$, respectively). MODIS DT land AODs also show the largest absolute MB ( 0.11 and 0.15 , respectively). In Fig. 3a, MODIS DT 10 and $3 \mathrm{~km}$ products, AHI ESR, and VIIRS AODs are all positively biased under low AOD conditions. In high AOD condition, AHI ESR does not show significant bias but MODIS DT and VIIRS still show increased positive biases. The MODIS DT, AHI ESR, and VIIRS algorithms assume a surface reflectance based on an empirical linear relationship between the visible and SWIR channels. Some studies indicate that MODIS C6 DT AOD does not have a noticeable positive MB (Levy et al., 2013; Sayer et al., 2014) globally or over East Asia, but other studies have reported a positive bias in MODIS C6 DT AOD over East Asia (Choi et al., 2018; Xiao et al., 2016), particularly over urban areas. Although the algorithm was modified to improve AOD accuracy over urban areas starting with Collection 6.1, MODIS DT still overestimates AOD compared with AERONET over East Asia (Gupta et al., 2016). In addition, the DT algorithm is designed for global retrievals and is not optimized for East Asia, which may explain the observed bias. Although the recent VIIRS algorithm calculated regional surface reflectance ratio between visible and SWIR as $0.1^{\circ} \times 0.1^{\circ}$ resolution from globally constant value to improve accuracy, the AOD pixel resolution is not degraded from a $0.75 \mathrm{~km} \mathrm{L1B}$ radiance resolution compared to other algorithms because they aim to provide the highest-resolution aerosol products for air quality applications. Therefore, additional filtering methods using spatial variability test or resolution degradation to increase aerosol signal than noise such as cloud is not available. Also, the obtained $0.1^{\circ} \times 0.1^{\circ}$ surface reflectance ratio database could still miss a smaller-scale urban surface heterogeneity.

In contrast, GOCI and AHI MRM AOD shows negative MB of -0.07 and -0.06 and the GOCI and AHI MRM aerosol retrieval algorithms obtain surface reflectance using the minimum reflectivity technique with monthly samples of Rayleigh-corrected reflectance (RCR). Although this technique is designed to obtain cloud-free and aerosol-free conditions by finding dark pixels within the composite dataset, the calculations can still be affected by aerosols and clouds, resulting in overestimated surface reflectance. The climatological surface-reflectance database of GOCI did not show significantly negative biased AOD between 2011 and 2015 according to the validation study of Choi et al. (2018). This negative bias in 2016 may be due to a sensor calibration issue or degradation, but the exact cause is difficult to diagnose and remains unknown.
MISR and MAIAC land AOD shows highest $R$ as 0.93 , small RMSE as 0.12 and 0.15 , and small MB as -0.02 and 0.05 , which result in a highest $f$ of 0.81 and 0.68 , respectively. A common characteristic between MISR and MAIAC is a multi-angle measurement capability (nine cameras of MISR and $16 \mathrm{~d}$ composite of MAIAC), which enables to distinguish surface and aerosol signals well. The MODIS DB used a hybrid method of surface reflectance ratio between visible and SWIR and pre-calculated surface reflectance using a minimum reflectivity technique, thus the bias is not as large as DT or GOCI. These DB and MISR results are consistent with previous studies (Choi et al., 2018; Garay et al., 2017; Sayer et al., 2014).

Because of the limited number of SONET sites, the $N$ is about $5 \%-7 \%$ of AERONET. Statistical metrics using SONET tend to be similar to the comparison with AERONET, but the values of metrics show worse agreement from SONET than from AERONET, especially in terms of RMSE and $f$, which is similar to the result of Choi et al. (2018). The AHI ESR, MODIS DT, and VIIRS show consistently positive MB from 0.08 to 0.15 . GOCI shows lower $R$ of 0.75 , higher RMSE of 0.22 , worse $f$ of 0.29 , and better MB of -0.03 , compared to the results with AERONET. It can be attributed to high variation in GOCI climatological surface reflectance uncertainty according to sites. MAIAC shows lowest RMSE of 0.15 and MB of 0.03 and highest $f$ of 0.67 . MISR also show high $f$ of 0.60 despite a small $N$ of 5. DB shows slightly lower $R$ of 0.82 , higher RMSE of 0.21 , similar MB of 0.08 , and lower $f$ of 0.46 compared to the results using AERONET. The aerosol retrieval algorithm, maintenance, and calibration of SONET are different from those of AERONET, thus it is difficult to explain the difference between the two results using AERONET and SONET. Chinese sites seem to have more difficulty retrieving aerosol properties from most satellite instruments.

\subsection{Ocean AOD validation using AERONET}

The target area for ocean aerosol retrievals differs among the various algorithms. The MODIS DT, MISR, MAIAC, and VIIRS algorithms retrieve aerosol properties only for dark ocean pixels, which means that surface pixels that are not completely dark, such as those containing shallow or turbid water, are masked. The GOCI/AHI Yonsei aerosol algorithms are also designed to retrieve aerosols over dark pixels, but they include moderately turbid water pixels by considering the climatological ocean surface reflectance based on minimum-reflectance techniques in the GOCI and AHI MRM algorithms and by considering chlorophyll $a$ concentrations in the AHI ESR algorithm. Because the ocean AOD validation was conducted using coastal AERONET AOD observations, $N$ is higher for GOCI and AHI (230-237) than for the LEO ocean AOD observations (13-111), with the exception of the VIIRS ocean AOD (252). Sun glint areas are also likely contribute to the difference in $N$. Single-angle view- 

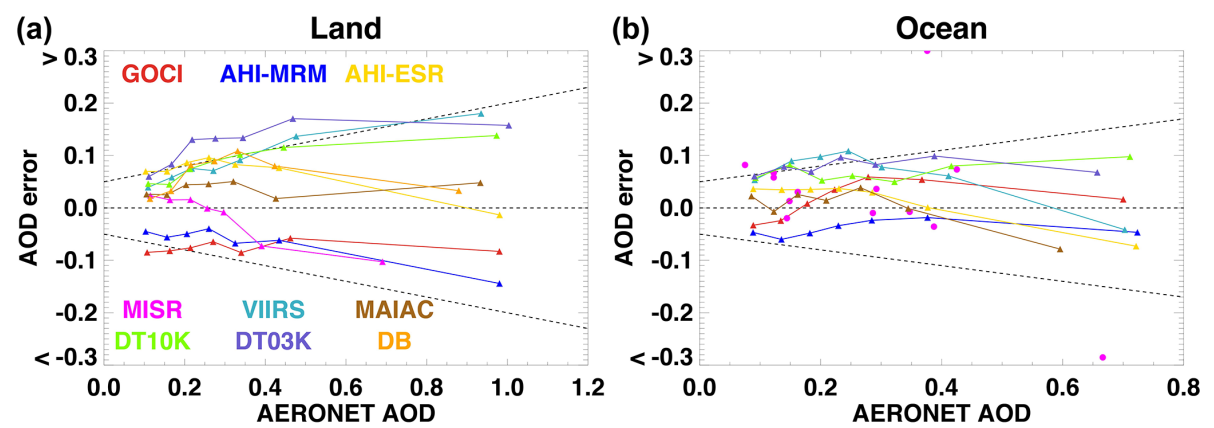

Figure 3. Comparison of observed (a) land and (b) ocean AOD errors for AERONET AOD. For each product, the total co-located data are grouped into seven bins according to AERONET AOD, except for MISR ocean AOD errors because of low co-location numbers. Each symbol indicates the median error for each co-located point, respectively. Black lines indicate zero difference and the $\mathrm{EE}_{\mathrm{DT}}$ range $\pm(0.05+0.15 \times$ AOD $A E R O N E T)$.

Table 2. IR cloud masking processes of the AHI YAER algorithm. Note that "high latitude" in step 1 corresponds to the 1st, 2nd, 9th, and 10th segments from the north of the AHI observation segments (a total of 10 segments for the full disk area) and "midlatitude to low latitude" in step 1 corresponds to the other 6 segments.

\begin{tabular}{lll}
\hline Steps & Brightness temperature (BT) difference (BTD) test conditions & Classifications \\
\hline 1 & BTD between 11.2 and $12.4 \mu \mathrm{m}$ & Cloud \\
& - Land: BT $(11.2 \mu \mathrm{m})-$ BT $(12.4 \mu \mathrm{m})<1.5 \mathrm{~K}$ \\
& - High-latitude ocean: BT $(11.2 \mu \mathrm{m})-$ BT $(12.4 \mu \mathrm{m})<-1.0 \mathrm{~K}$ & \\
& - Midlatitude to low-latitude ocean: BT $(11.2 \mu \mathrm{m})-$ BT $(12.4 \mu \mathrm{m})<0.5 \mathrm{~K}$ & \\
\hline 2 & BTD between 12.4 and $13.3 \mu \mathrm{m}$ & High-level cloud \\
& - Land and ocean: BT $(12.4 \mu \mathrm{m})-$ BT $(13.3 \mu \mathrm{m})<11 \mathrm{~K}$ & Low-level cloud \\
\hline 3 & $\begin{array}{l}\text { BTD between } 8.6 \text { and } 6.9 \mu \mathrm{m} \\
\end{array}$ & -Land and ocean: BT $(8.6 \mu \mathrm{m})-$ BT $(6.9 \mu \mathrm{m})<-10 \mathrm{~K}$ \\
\hline 4 & $\begin{array}{l}\text { BTD between 11.2 and } 8.6 \mu \mathrm{m} \\
\end{array}$ & Cirrus cloud \\
\hline
\end{tabular}

ing LEO satellite measurements, such as MODIS, exclude bright ocean surface pixels because of sun glint close to the nadir, where most pixels are screened out, as is evident in Fig. 3. This occurs daily near the Korean Peninsula and results in most transported aerosol plumes around the Korean Peninsula not being measured with continuous spatial coverage. Although the VIIRS is also a single-angle viewing instrument, its broader swath results in more ocean pixels being retrieved than is the case for MODIS. The MISR instrument minimizes sun glint effects over ocean pixels through multi-angle viewing but still has low $N$ because of its narrow swath. The sun glint areas of the GEO satellites are located near the Equator, have a circular shape, and shift from east at sunrise to west at sunset. Most Southeast Asian countries, including the Philippines, Malaysia, and Thailand, are affected by this sun glint screening in ocean AOD from GEO satellites, whereas most northeastern Asian countries, including China, South Korea, and Japan, are unaffected. Thus, GOCI and AHI provide spatiotemporally continuous aerosol measurements across land and ocean over northeast- ern Asia where dense aerosol plumes of varying composition are transported from mainland Asia to the Pacific.

According to most validation metrics, ocean AOD products are more accurate than those over land. This difference leads to generally lower errors for ocean AOD compared to their respective over land retrievals, based on AERONET AOD measurements (Fig. 3b). The sign of the ocean AOD error in the low AOD range is the same as that of the land AOD error for all products, i.e., negative in GOCI and AHI MRM and positive in DT and AHI ESR. The MAIAC, VIIRS, GOCI, and AHI products have high accuracy, as evidenced by a low RMSE (0.12-0.13) and a near-zero MB $(-0.03$ to 0.04$)$, resulting in a high $f(0.612-0.769)$. The MODIS DT $3 \mathrm{~km}$ ocean AOD product has a larger positive MB (0.10) than the $10 \mathrm{~km}$ product (0.06), similar to MODIS DT land AOD.

In summary, most LEO and GEO aerosol products over East Asia are highly accurate and based on a comparison with AERONET with high $R(0.84-0.93)$ and low RMSE (0.120.17 ) but have unique bias patterns related to the surfacereflectance assumptions in each algorithm. This leads to pos- 
Table 3. Validation statistics for land AOD products using AERONET.

\begin{tabular}{lrrrrc}
\hline Products (resolution) & $N$ & $R$ & RMSE & MB & $f$ within EE DT \\
\hline GOCI (6 km) & 4292 & 0.91 & 0.15 & -0.07 & 0.48 \\
AHI MRM (6 km) & 19160 & 0.91 & 0.14 & -0.06 & 0.58 \\
AHI ESR (6 km) & 19174 & 0.90 & 0.16 & 0.07 & 0.54 \\
MODIS DT (10 km) & 988 & 0.87 & 0.22 & 0.11 & 0.51 \\
MODIS DT (3 km) & 1312 & 0.88 & 0.23 & 0.15 & 0.43 \\
MODIS DB (10 km) & 851 & 0.88 & 0.17 & 0.07 & 0.53 \\
MODIS MAIAC (1 km) & 1348 & 0.93 & 0.15 & 0.05 & 0.68 \\
MISR (4.4 km) & 114 & 0.93 & 0.12 & -0.02 & 0.81 \\
VIIRS $(0.75 \mathrm{~km})$ & 800 & 0.87 & 0.16 & 0.07 & 0.59 \\
\hline
\end{tabular}

Table 4. Validation statistics for land AOD products using SONET.

\begin{tabular}{lrrrrc}
\hline Products (resolution) & $N$ & $R$ & RMSE & MB & $f$ within EE $_{\text {DT }}$ \\
\hline GOCI $(6 \mathrm{~km})$ & 287 & 0.75 & 0.22 & -0.03 & 0.29 \\
AHI MRM (6 km) & 922 & 0.85 & 0.17 & -0.03 & 0.43 \\
AHI ESR (6 km) & 926 & 0.89 & 0.18 & 0.09 & 0.58 \\
MODIS DT $(10 \mathrm{~km})$ & 50 & 0.91 & 0.21 & 0.08 & 0.48 \\
MODIS DT $(3 \mathrm{~km})$ & 83 & 0.87 & 0.25 & 0.15 & 0.37 \\
MODIS DB $(10 \mathrm{~km})$ & 59 & 0.82 & 0.21 & 0.08 & 0.46 \\
MODIS MAIAC $(1 \mathrm{~km})$ & 89 & 0.88 & 0.15 & 0.03 & 0.67 \\
MISR (4.4 km) & 5 & 0.99 & 0.18 & -0.09 & 0.60 \\
VIIRS $(0.75 \mathrm{~km})$ & 58 & 0.90 & 0.23 & 0.11 & 0.43 \\
\hline
\end{tabular}

itive biases for MODIS DT and AHI ESR AOD, negative biases for GOCI and AHI MRM AOD, and small biases for the other products. The coverage also differs between singleangle and multi-angle measurements, and with swath size and orbit types, resulting in a range of $N$ values.

\section{Transport events during the campaign}

\subsection{Analysis of the period 18-21 May 2016 over Hokkaido, Japan}

Noticeable aerosol transport was observed over Hokkaido, Japan, during the period 18-21 May 2016. Although GOCI and AHI AODs were retrieved at $1 \mathrm{~h}$ and $10 \mathrm{~min}$ temporal resolutions, respectively, only data for 09:30 and 13:30 LT are presented in Fig. 4 for comparison with MODIS, MISR, and VIIRS distributions. A time series of satellite AODs colocated with AERONET AOD from Hokkaido University, located at $43.08^{\circ} \mathrm{N}, 142.34^{\circ} \mathrm{E}$ and $43.08 \mathrm{~m}$ above sea level, is presented in Fig. 5.

As the dense smoke aerosol plume (AOD > 2.0 at the center) generated from the Russian forest fires was transported to Hokkaido continuously from morning to afternoon on 18 May, AERONET AOD at Hokkaido University increased rapidly from 0.1 to 1.4 , and the GOCI and AHI successfully detected this abrupt increase. The MODIS and VIIRS instruments also detected increasing AOD accurately, but the first and last AODs during the day were 0.6 and 1.1 at 10:30 and 13:30 LT, respectively, and therefore did not capture the full diurnal variation detected by AERONET, GOCI, and AHI. The increase in AOD at Hokkaido on 18 May was anticipated from the southward movement of the plume revealed by the GOCI and AHI measurements. On 19 May, the plume remained over Hokkaido and the spatial distribution changed little during daylight hours. The AOD observed by AERONET decreased from 1.3 to 0.9 , and the GOCI and AHI instruments detected this change but with a slight overestimation during the morning. The VIIRS and MODIS DT and DB AODs are higher by about 1.5 and the MISR AOD is lower than the AERONET value by 0.9. On 20 May, the AERONET AOD began to increase to 1.0 at 06:00 LT, peaked up to 1.3 at 12:00-13:00 LT, and sharply decreased down to $\sim 0.6$ at 18:00 LT. The GOCI and AHI retrievals again followed this variation well, beginning at 09:00 LT. The AHI also detected the AOD peak well, but the MODIS DT and DB overestimated AOD compared with AERONET. The pixels involved did not include cloud edges, so this difference in AOD was not due to cloud contamination. AE between 440 and $870 \mathrm{~nm}$ at Hokkaido university AERONET site was around 1.95 , and SSA at $440 \mathrm{~nm}$ was about 0.9 , which means that those aerosols were small particle size and less absorbing then aging smoke plume. On 21 May, the dense AOD plume was bifurcated into two: one moved out to Pacific Ocean and the other to the southwest of Hokkaido. The AERONET 
Table 5. Validation statistics for ocean AOD products using AERONET.

\begin{tabular}{lrrrrc}
\hline Products (resolution) & $N$ & $R$ & RMSE & MB & $f$ within EE $_{\text {DT }}$ \\
\hline GOCI $(6 \mathrm{~km})$ & 1766 & 0.88 & 0.12 & 0.03 & 0.68 \\
AHI MRM $(6 \mathrm{~km})$ & 7575 & 0.87 & 0.13 & -0.03 & 0.64 \\
AHI ESR $(6 \mathrm{~km})$ & 7663 & 0.84 & 0.13 & 0.02 & 0.76 \\
MODIS DT $(10 \mathrm{~km})$ & 85 & 0.91 & 0.12 & 0.06 & 0.61 \\
MODIS DT $(3 \mathrm{~km})$ & 205 & 0.87 & 0.16 & 0.10 & 0.49 \\
MODIS MAIAC $(1 \mathrm{~km})$ & 248 & 0.88 & 0.10 & 0.00 & 0.72 \\
MISR (4.4 km) & 13 & 0.63 & 0.15 & 0.04 & 0.77 \\
VIIRS $(0.75 \mathrm{~km})$ & 252 & 0.84 & 0.12 & 0.04 & 0.69 \\
\hline
\end{tabular}

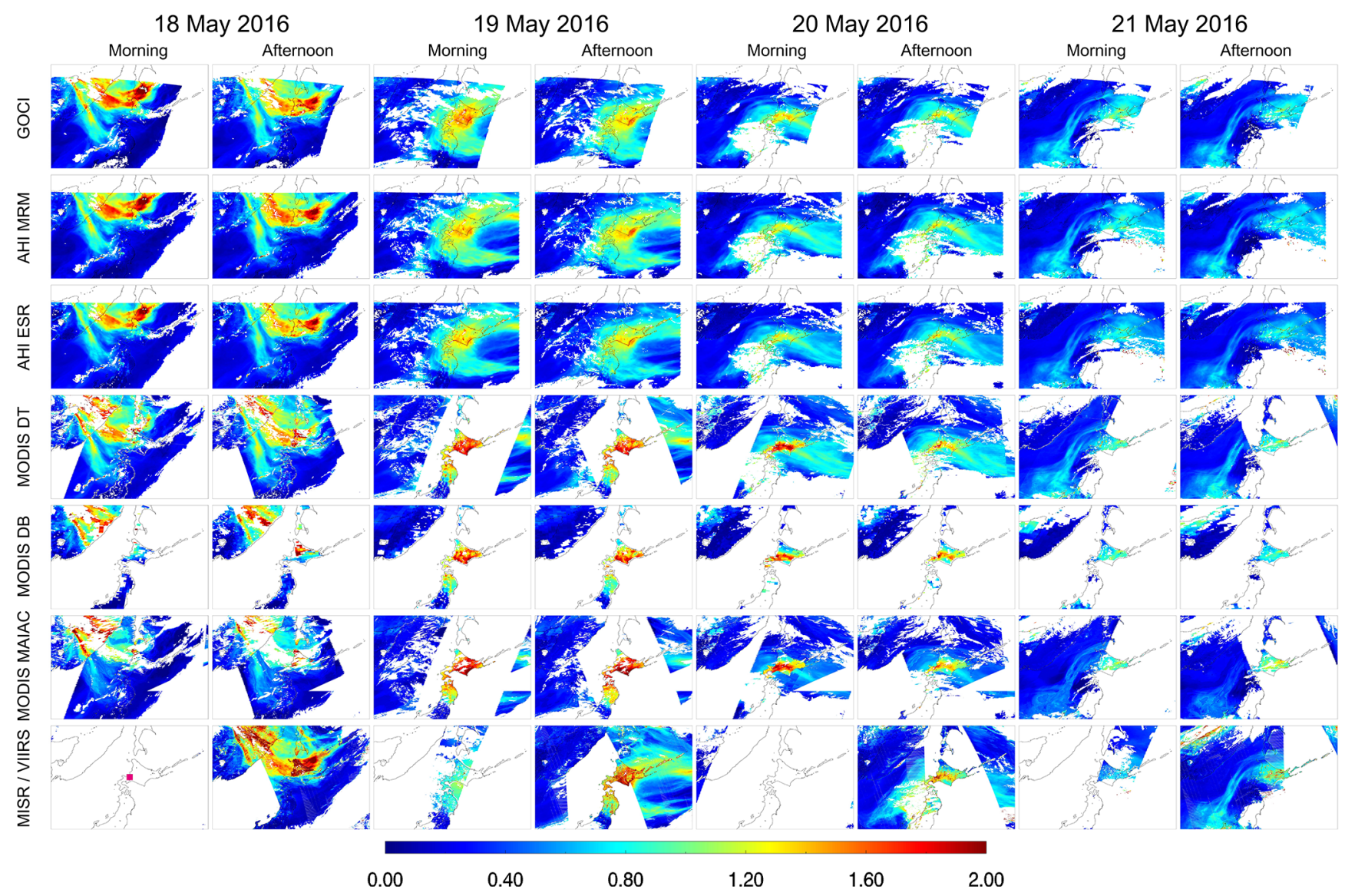

Figure 4. AOD distributions from GOCI, AHI MRM, AHI ESR, MODIS DT03K, MODIS DB, MODIS MAIAC, MISR, and VIIRS over the Hokkaido region during 18-21 May 2016. Note that morning and afternoon AODs for GOCI and AHI refer to 10:30 and 13:30 LT, respectively, and for MODIS these refer to the Terra and Aqua measurements, respectively. MISR only has a morning measurement and VIIRS only has an afternoon measurement. The pink symbol in a bottom-left panel shows the location of the Hokkaido University AERONET site.

AOD over the Hokkaido University site decreased slightly from 0.6 to 0.4 and most products detected these low AOD conditions well.

It is very hard to figure out the exact reason for overestimation of MODIS DT, DB, VIIRS, and MAIAC AOD over this plume despite reasonable accuracy from AERONET validation. The statistical metrics of MODIS DT, DB, MAIAC, and
VIIRS validation at Hokkaido University site during the campaign show very high $R(0.96-0.98)$ and a small offset of the linear regression equation $(-0.03$ to 0.03$)$ but with a higher slope than one (1.22-1.43) revealing high MB (0.12-0.18). The small offset of the linear regression equation represents lower surface reflectance error in AOD validation. With this condition, higher slope generally means that AOD overes- 


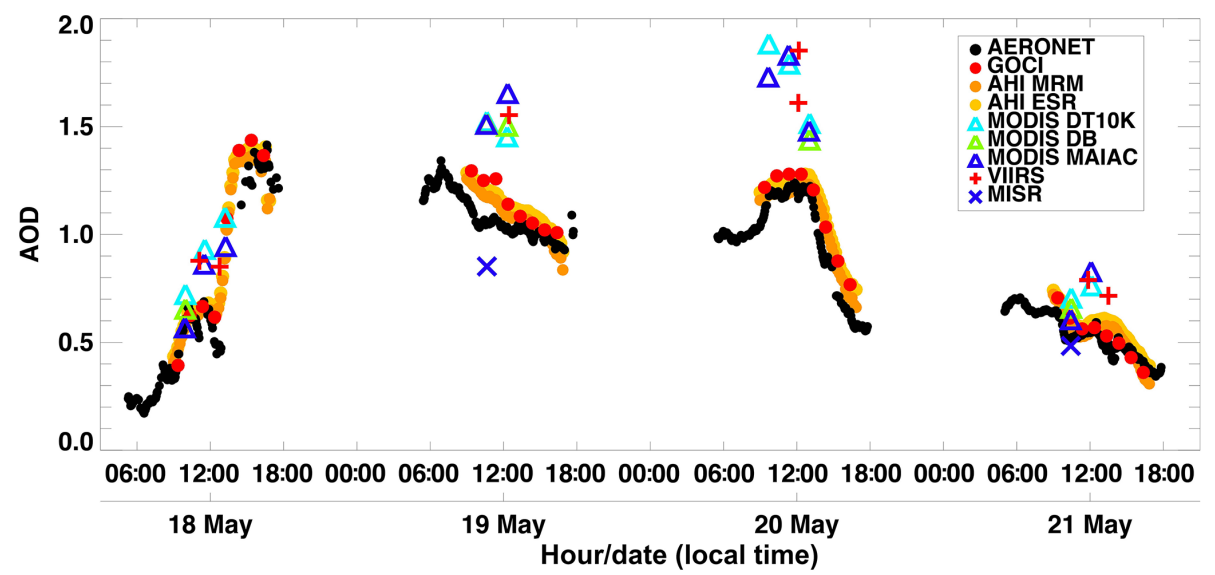

Figure 5. Time series of multiple satellite AODs and AERONET AOD at the Hokkaido University site during 18-21 May 2016.

timation due to the aerosol model assumption (Hyer et al., 2011) if cloud masking is working well. This transport case results in also high AOD, where uncertainty of the aerosol model can be emphasized. Therefore, a possible reason for overestimation is due to an aerosol model assumption such as microphysical properties.

It can be summarized that overall evaluation is not matched with an individual site or case over East Asia because of the complexity of surface conditions and dynamic aerosol types. Additionally, MODIS and VIIRS do not provide spatially continuous AOD distributions because of sun glint masking over ocean areas near Hokkaido, making identification of plume sources and transport patterns difficult. In contrast, GEO can avoid sun glint area over midlatitude areas. Sun glint is a bright ocean surface due to the reflected solar radiance, which is brighter in nadir viewing angles. Due to the measurement geometry, single-angle-viewing LEO sensors such as MODIS and VIIRS generally have the sun glint pixels in the middle of the swath. In contrast, GEO has the sun glint pixels as a circle shape centered at the Equator because GEO sensors are located at the Equator. Because of multi-temporal measurement without sun glint pixels, GEO such as GOCI and AHI can detect these transported aerosol plumes across ocean with more continuous spatiotemporal distribution than LEO.

\subsection{Analysis of 25 May and 5 June 2016 cases over the Yellow Sea and Korean Peninsula}

Next, two heavy aerosol loading cases over the Korean Peninsula are analyzed (as in Fig. 6). During the campaign, the first noticeable increase in PM above the South Korean national air quality standard $\left(50 \mu \mathrm{g} \mathrm{m}^{-3}\right.$ before April 2018; now $35 \mu \mathrm{g} \mathrm{m}^{-3}$ ) occurred on 25 May 2016 and resulted in dense aerosol conditions around the Korean Peninsula. In the morning, high AOD values ranging from 0.8 to 2.0 were measured by GOCI, AHI, and MISR over the Yellow Sea located to the west of the Korean Peninsula. A few land pixels in the southwestern Korean Peninsula adjacent to this dense aerosol plume also showed high AOD values of $\sim 1.0$. Land pixels in the northwestern Korean Peninsula and adjacent ocean pixels were screened out because of clouds. Very low AOD values $(0.0-0.3)$ were observed at other land pixels over the eastern Korean Peninsula Most ocean AOD pixels are screened out from MODIS DT and MODIS MAIAC because of sun glint. MISR detects the plume over the Yellow Sea, and is not affected by sun glint with multi-angle imaging capability. As the plume continuously moved eastward, high AOD plume entered over land pixels in the Korean Peninsula and a steep zonal gradient of AOD was evident near $127^{\circ} \mathrm{E}$ in the afternoon. To evaluate the temporal AOD transportation quantitatively, a Hovmöller diagrams of GOCI and AHI MRM AOD pixels within a box area $\left(35-38^{\circ} \mathrm{N}, 123-128^{\circ} \mathrm{E}\right)$ were constructed by averaging meridionally at a $0.02^{\circ}$ longitude interval as shown in Fig. 7a and c. The peak at 09:30 LT was located at $\sim 123.5^{\circ} \mathrm{E}$ and moved continuously eastward to $123.8,124.4,124.8,125.0,125.5,125.8$, and $126.3^{\circ} \mathrm{E}$ at $1 \mathrm{~h}$ intervals until 16:30 LT. This transport corresponds to westerly zonal wind direction at $850 \mathrm{hPa}$ of the fifth generation of European Centre for Medium-Range Weather Forecasts (ECMWF) atmospheric reanalyses of the global climate (ERA5; Copernicus Climate Change Service, 2017). The AOD over the Yellow Sea $\left(123-126^{\circ}\right.$ E) decreased from 1.2 to 0.9 as the plume passed over. In contrast, the AOD over the Korean Peninsula (126-129.5 E) increased gradually, particularly over $127^{\circ} \mathrm{E}$ in the western Korean Peninsula where it increased from 0.3 to 0.8 . The eastern Korean Peninsula $\left(128-129.5^{\circ} \mathrm{E}\right)$ was not affected by the plume during daylight hours, and the AOD remained low (0.2-0.3). More detailed features can be found in the higher temporal resolution of AHI than in GOCI. The transport speed of the plume center $(A O D>1.1)$ can be calculated as about $39 \mathrm{~km} \mathrm{~h}^{-1}$ (e.g., $10.9 \mathrm{~m} \mathrm{~s}^{-1}$ ) from 123.5 to $126.0^{\circ} \mathrm{E}$ during 09:00-15:00 LT, which is similar to the wind speed at $850 \mathrm{hPa}$ in Fig. $7 \mathrm{a}$ and c. 

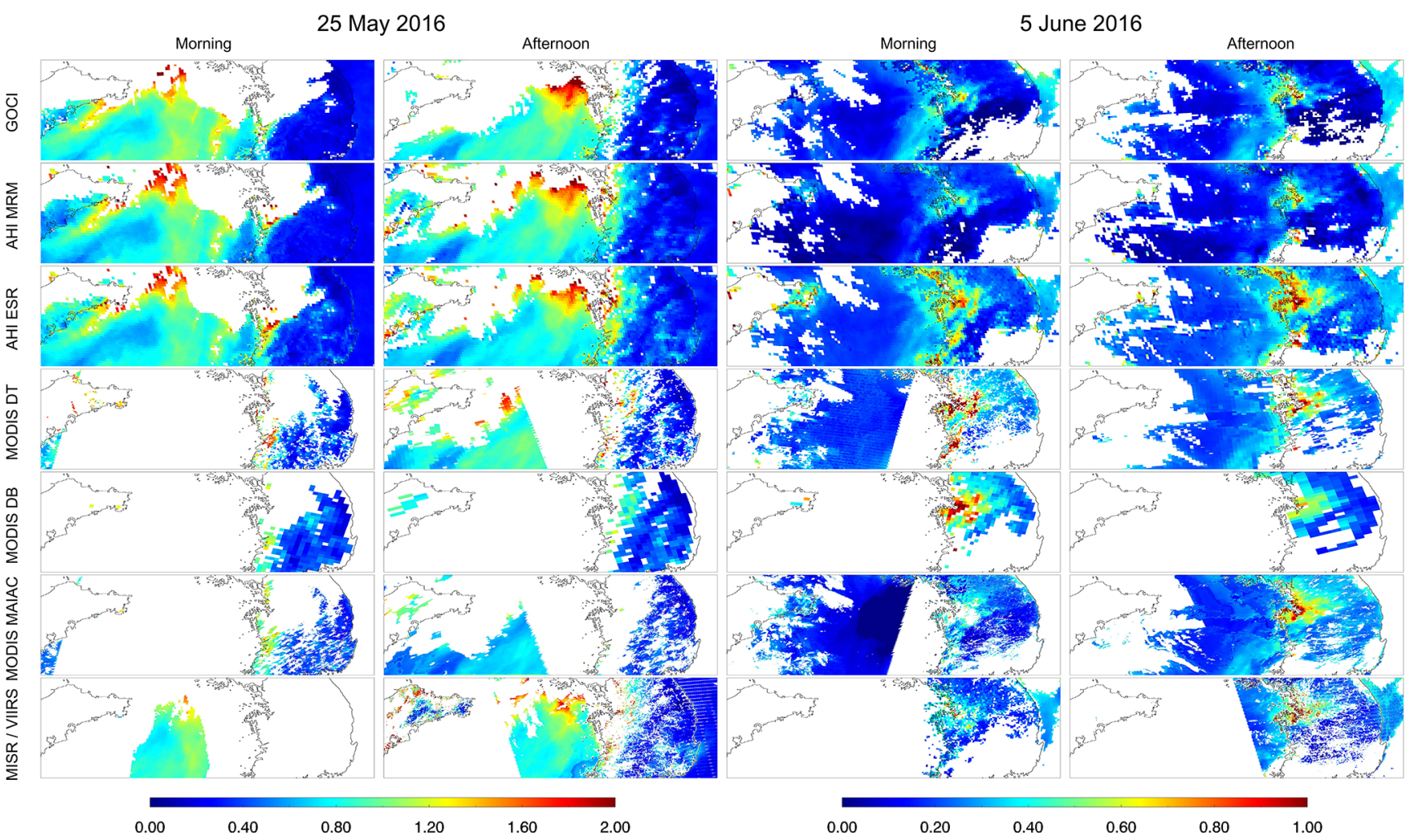

Figure 6. AOD distributions from GOCI, AHI MRM, AHI ESR, MODIS DT03K, MODIS DB, MODIS MAIAC, MISR, and VIIRS over the Yellow Sea and Korean Peninsula $\left(35-38^{\circ} \mathrm{N}, 120-130^{\circ} \mathrm{E}\right)$ at 25 May and 5 June 2016. The local time of morning and afternoon measurements is identical with Fig. 4.

Compared with conditions on 25 May 2016, the overall AODs on 5 June 2016 over the Yellow Sea and Korean Peninsula was low (0.1-0.2) and the AOD over the Seoul Metropolitan Area (SMA) near $37^{\circ} \mathrm{N}, 127^{\circ} \mathrm{E}$ was about 0.4 0.6 from GOCI and AHI MRM in the morning (as in Fig. 6). The focus here is on SMA AOD, which increased up to 1.0 and dispersed out to surrounding areas in the afternoon. The quantities of MISR AOD in the morning (around 0.4-0.5) and VIIRS AOD in the afternoon (around 1.0) over the SMA is analogous with GOCI, AHI MRM, and MODIS MAIAC. In contrast, changes in AOD was less significant from AHI ESR, MODIS DT, and MODIS DB because morning AODs were higher (around 1.0) than others (around 0.4-0.5). Because the periphery of the SMA remained under low AOD conditions and aerosol transport from China through the Yellow Sea was not detected, this increase can be attributed to local emissions. A distinct pattern is evident in the temporal changes of meridional mean AODs shown in Fig. $7 \mathrm{~b}$ and $\mathrm{d}$. The mean AODs in the region $125.5-127.0^{\circ} \mathrm{E}$ gradually increased from 0.2 to 0.5 , whereas the AODs in other areas, including the Yellow Sea and eastern Korean Peninsula, remained constant during daylight hours. Unlike conditions on 25 May, the dense aerosol plume on 5 June grew rapidly over a short period of time from local-area emissions and was transported to the Yellow Sea. The wind was east- erly and speed in the afternoon was weaker than the case of 25 May 2016, which resulted in less dispersion patterns of local emissions compared to the previous case.

The two events analyzed in this section involved rapid changes in hourly AOD but have noticeably different spatiotemporal characteristics, leading to high AOD conditions that are attributed to either long-range transboundary transport from China or local emissions in South Korea (Lee et al., 2019). To accurately assess these types of events, spatiotemporally continuous measurements with minimal data gaps are required, which are currently possible only from GEO measurements.

\section{Comparison of spatial distribution and daily AOD integration}

\subsection{Averaging daily and campaign period AOD on a common grid}

Because the various satellite AOD products were validated using AERONET, results are only valid for specific ground sites. A comparison between satellite products can provide the relative difference in AOD for each pixel, but a direct comparison between satellite products of level 2 (L2) data 

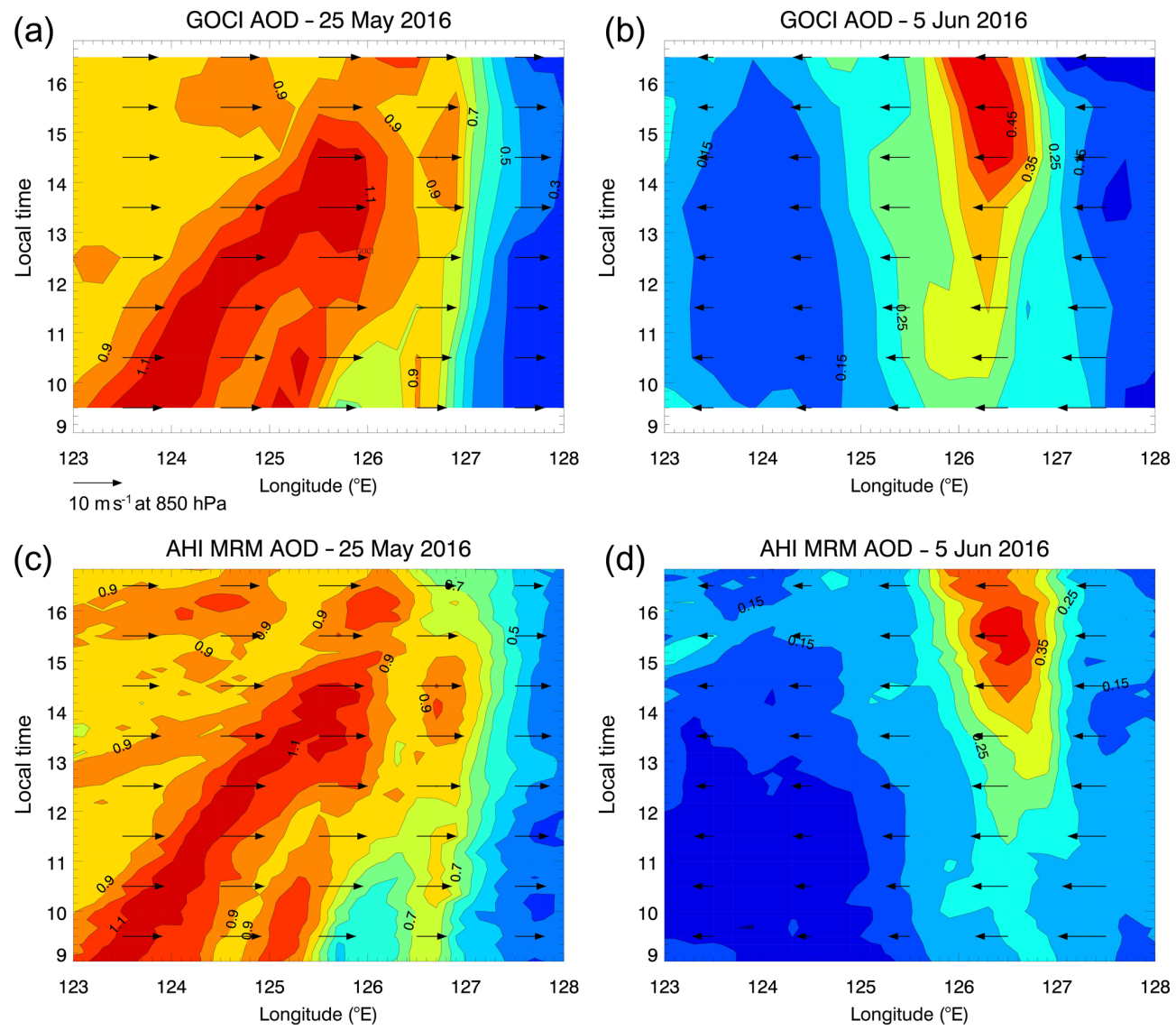

Figure 7. Meridional mean GOCI AOD over the Yellow Sea and the Korean Peninsula $\left(35-38^{\circ} \mathrm{N}, 123-128^{\circ} \mathrm{E}\right)$ at $0.2^{\circ}$ longitude intervals on (a) 25 May and (b) 5 June 2016. Meridional mean AHI MRM AOD on (c) 25 May and (d) 5 June 2016. Overlapped arrows represent meridionally averaged zonal wind at $850 \mathrm{hPa}$.

is difficult because they differ in spatial coverage, measurement time, and spatiotemporal resolution. For this reason, each L2 AOD product was regenerated as a daily average value on the spatial grid of the level 3 (L3) products. Although some products are available in the L3 format, the methods and criteria used in their L3 calculation differ considerably. Thus, a simple and commonly used method is applied here to generate daily L3 AOD. The spatial domain is set to $20-50^{\circ} \mathrm{N}, 110-150^{\circ} \mathrm{E}$, and the grid resolution is set to $0.5^{\circ} \times 0.5^{\circ}$. For the aggregation, textural filtering described by Zhang and Reid (2006) and Hyer et al. (2011) is used to reduce random error through averaging. Then, AOD pixels within a grid cell are filtered if the number of retrieved AOD pixels is $<3$ or the coefficient of variation in AOD within the grid cell is $>0.5$ and the mean AOD is $>0.2$. The number of pixels used to calculate one $0.5^{\circ} \times 0.5^{\circ}$ pixel is determined by the spatial resolution of the L2 AOD data and the number of filtered pixels. After aggregation of each distribution to the L3 grid, the distributions for each day are averaged to a daily mean value. Temporal resolution and swath determine the maximum number of temporal samples used in the daily mean value: 8 for GOCI ( $1 \mathrm{~h}$ temporal resolution), 47 for AHI (10 min temporal resolution), 2-4 for MODIS (Aqua and Terra), and 1 or 2 (swath-overlapping pixels) for VIIRS and MISR. Note that the $10 \mathrm{~km}$ product is used for MODIS DT instead of $3 \mathrm{~km}$ because of its lower positive bias.

\subsection{Comparison of observation frequency during the campaign}

The number of $\mathrm{L} 2 \mathrm{AOD}$ pixel samples within each $0.5^{\circ} \times 0.5^{\circ}$ grid cell over $20-50^{\circ} \mathrm{N}, 110-150^{\circ} \mathrm{E}$ during the campaign period is calculated and the maximum number of them is denoted as $N_{\max } . N_{\max }$ is high when the spatial and temporal resolutions are high and when fewer pixels are masked because of the presence of clouds or uncertain surface reflectance. The calculated mean AOD can be more statistically representative when $N_{\max }$ is high. Highly uncertain AOD values can be removed during the spatiotemporal averaging steps, but these pixels can still lead to high uncertainty when temporally averaged mean AOD is calculated from only a few samples. Thus, we can determine the reliability of AOD values for each region and for each product using the number of L2 pixel samples. The $N_{\max }$ can be sorted 
in descending order as follows: MAIAC $\left(1.3 \times 10^{5}\right)$, AHI $\operatorname{ESR}\left(7.3 \times 10^{4}\right)$, AHI MRM $\left(7.1 \times 10^{4}\right), \operatorname{VIIRS}\left(6.2 \times 10^{4}\right)$, GOCI $\left(1.2 \times 10^{4}\right)$, MISR (668), MODIS DT $10 \mathrm{~km}(661)$, and MODIS DB (556). The high $N_{\max }$ of MAIAC and VIIRS is from a high spatial resolution of 1 and $0.75 \mathrm{~km}$, respectively, and the high $N_{\max }$ of AHI and GOCI is from a high temporal resolution of $10 \mathrm{~min}$ and $1 \mathrm{~h}$, respectively.

The number of L2 pixels for each grid can be normalized by $N_{\max }$ to compare relative sampling frequency (RSF) ranged from 0 to 1 between products as Fig. 8. Most products have more samples over the Korean Peninsula and eastern China than over Japan. A possible reason for lower sampling in Japan is higher amount of cloud due to its adjacency of the Pacific Ocean, or a combination of lower AOD condition and very high mountains and therefore slope effects, plus high spatial variance of AOD with higher values in the valleys and lower over the mountain peaks. The RSF of GOCI is about 0.6-0.7 over the Korean Peninsula, with some discontinuity between land and ocean. The negative GOCI AOD bias under low AOD conditions from land surface reflectance effects results in retrieved AOD values of less than -0.05 , which are screened out of the final product. This bias has less of an effect on the land pixels of GOCI. As AHI AOD is not affected by these errors, continuously high RSF over land and ocean surfaces exists on the Korean Peninsula. The RSF of MISR includes a discontinuity between paths that results in a more discontinuous AOD distribution compared to the other products. The MODIS DT and DB have similar distributions of RSF over land, except over Manchuria (0.6-0.8 of DB but $0.0-0.2$ of DT). The MODIS DT has small RSF as $0.0-0.4$ over the Yellow Sea because of turbid water and sun glint masking. The RSF distribution of VIIRS is similar to that of MODIS DT but is higher over the ocean because of its broad swath, thereby at times avoiding sun glint . MAIAC shows similar pattern of RSF with VIIRS but with a higher value over the bright Manchurian surface that is close to 1. Also, all products show low RSF over southeastern China (bottomleft land area of each panel) as $0.0-0.2$, which can result in higher uncertainty over that area even if all products are integrated.

\subsection{Daily AOD fusion}

Retrieved satellite AOD errors can be classified into two types: random error and bias. Although some algorithms, such as the optimal estimation method, can provide an estimated random error or uncertainty quantitatively (e.g., Jeong et al., 2016), the random error and bias of retrieved AOD can be assessed only over AERONET sites, making it difficult to quantify and validate uncertainties for all pixels. As errors were found to be distributed equally around zero for land and ocean surfaces during the validation using AERONET data, the combined AOD is calculated by selecting the median value from the daily $0.5^{\circ} \times 0.5^{\circ}$ gridded mean AOD among different products. The reason for selecting median value among products is based on well-distributed bias patterns from Fig. 3 and to exclude extreme values. The mean of daily AOD fusion result is presented in Fig. 9, and there are patterns of high AOD (0.8-1.0) in eastern China, low AOD in Japan (0.2-0.4), high AOD in the western Korean Peninsula (0.5-0.6), and low AOD in eastern South Korea $(0.2-0.4)$. The ratio to be selected median value to represent fusion AOD for each daily grid can be calculated per each product. When the area is limited to the smallest GOCI domain, the selection ratio can be sorted, in descending order, as follows: AHI ESR (27.2\%), AHI MRM (25.2\%), GOCI (16.2\%), MODIS MAIAC (10.8\%), VIIRS (10.7\%), MODIS DT (5.7\%), MODIS DB (2.8\%), and MISR (1.4\%). Note that MODIS DB can be underestimated due to the lack of ocean AOD. Because GEO measurements yield more samples that contribute to the daily representative AOD, the AHI and GOCI account for a higher fraction of the combined AOD. Among LEO products, MAIAC and VIIRS have higher spatial resolution with a wide swath and show higher selection ratio.

Evaluation of the daily average AOD for each product and the combined AOD using daily AERONET AOD is presented in Fig. 10. The closest grid point to each AERONET site is selected for the comparison. The number of selected grid points is 870 (AHI), 768 (GOCI), 677 (MODIS MAIAC), 658 (VIIRS), 436 (MODIS DT), 303 (MODIS DB), and 106 (MISR). Most products show similar bias patterns to the level 2 pixel-level validation. For instance, GOCI is negatively biased and MODIS DT is positively biased. However, when we combined all of these products for the fusion AOD, it has a higher $f(0.61)$ than the individual products, except for MISR (0.77) and MAIAC (0.65), and a high $N$ (869), low RMSE (0.16), and high $R$ (0.87). This satisfies our objective of generating a more representative AOD field including more pixels with high accuracy than the individual AOD products do on their own.

\subsection{Comparison of difference between each product and fusion AOD product}

The validation using AERONET is only available over a few specific grids. Thus, the difference between each product AOD and fusion AOD of Fig. 9 is calculated and compared (as in Fig. 11). GOCI shows relatively low AOD compared to fusion AOD for land pixels over the Korean Peninsula and Japan by about 0.2 and over southeastern China by up to 0.4 and higher AOD over Manchuria by about 0.3 . AHI MRM and ESR show the least difference overall over most areas and this is related to the highest selection ratio of AHI products for fusion AOD. An interesting feature is that positivenegative pattern is the opposite between MRM and ESR over most grids, which was found to agree with improved accuracy in AHI when these two products are merged in Lim et al. (2018). The narrow swath of MISR leads to a broad gap between paths, and the discontinuity of the MISR L2 
(a) GOCI

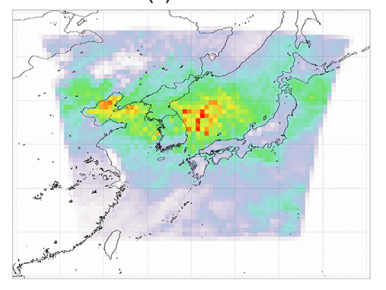

(e) VIIRS

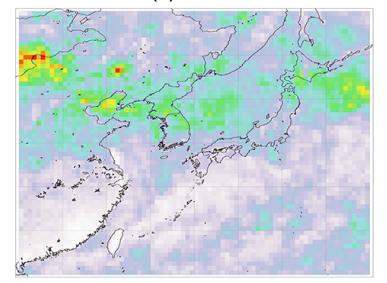

(b) AHI MRM

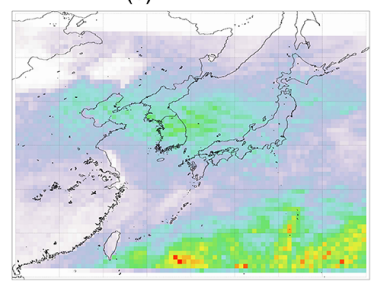

(f) MODIS DT

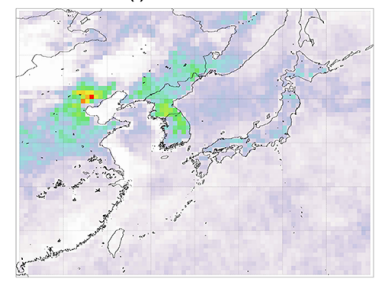

(c) AHI ESR

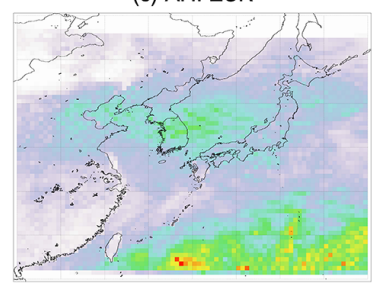

(g) MODIS DB

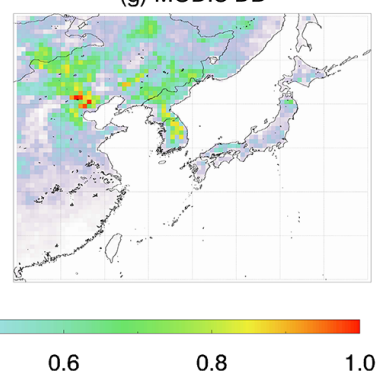

(d) MISR

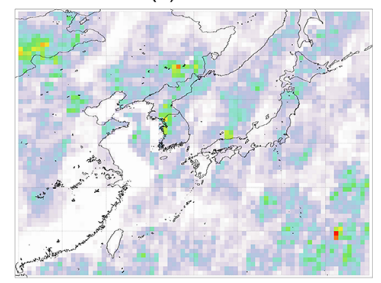

(h) MODIS MAIAC

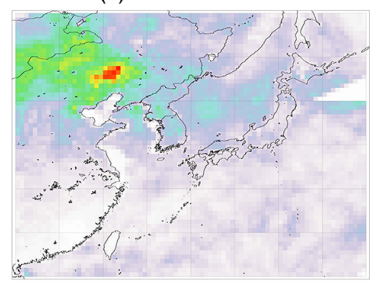

0.0

0.2

0.4

Figure 8. Relative sampling frequency of L2 AOD pixels used to calculate mean AOD of (a) GOCI, (b) AHI MRM, (c) AHI ESR, (d) MISR, (e) VIIRS, (f) MODIS DT10K, (g) MODIS DB, and (h) MODIS MAIAC. The area of map corresponds to 20-50 $\mathrm{N}, 110-150^{\circ} \mathrm{E}$.

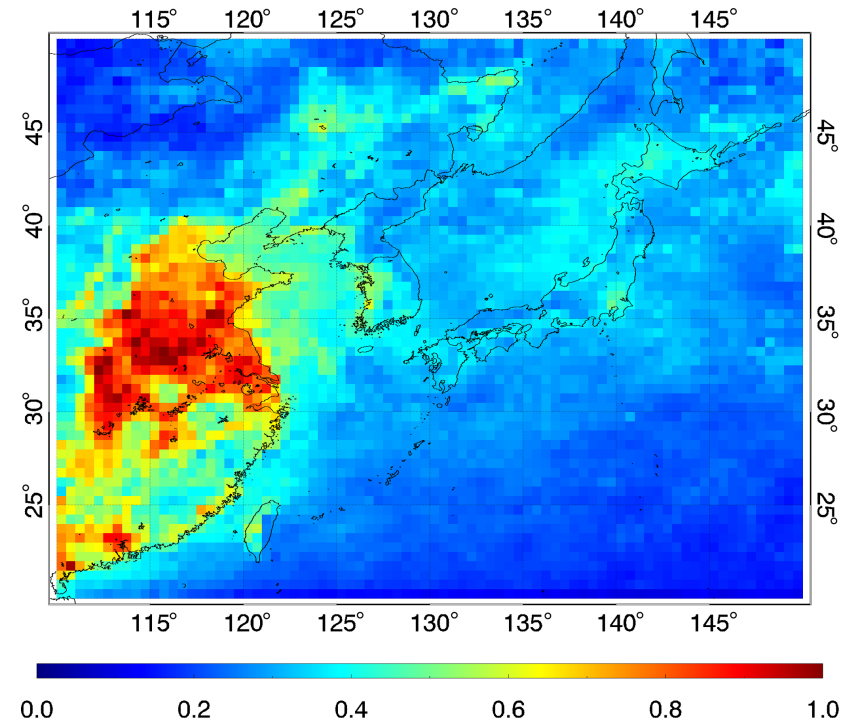

Figure 9. Mean of daily fusion AOD $\left(0.5^{\circ} \times 0.5^{\circ}\right.$ latitudelongitude) during the KORUS-AQ campaign period (1 May to 12 June 2016).

AOD data is noticeable along the swath boundary. More period averaging seems to be required to analyze MISR AOD characteristics compared to others. The difference between VIIRS AOD and fusion AOD is quite similar to that of AHI ESR, as there is higher AOD over southeastern China (0.3) and lower AOD over northeastern China (0.2). MODIS DT shows high noise patterns over the Yellow Sea compared to others, which can be related to the lower sampling frequency due to sun glint and turbid or shallow water masking with coarse pixel resolution $(10 \mathrm{~km})$. MODIS DB shows similar pattern to GOCI over land except for Manchuria. Because Manchuria has a bright surface, MODIS DB, MODIS MAIAC, VIIRS, and MISR can have better accuracy than others. The MAIAC generally shows less difference with fusion AOD except for higher AOD over ocean grids near the Chinese coast. Lyapustin et al. (2018) also notes that current masking of MAIAC misses several coastal waters with high sediments where AOD retrievals often show a high bias.

\section{Discussion and conclusions}

In this study, we compare spatiotemporal characteristics of three GEO AOD products (GOCI, AHI MRM, and AHI ESR) and five LEO AOD products (MODIS DT, MODIS DB, MODIS MAIAC, MISR, and VIIRS) and validate each product using the AERONET version 3 and SONET dataset for the 2016 KORUS-AQ campaign. Most AOD products have high accuracy and wide coverage over East Asia, but each have individual unique characteristics (e.g., detailed accuracy and sampling frequency). Although Choi et al. (2018) showed that GOCI AOD is reliably accurate for the period 2011-2015, it is negatively biased during the 2016 campaign period. This difference in accuracy may be attributable to changes in climatological surface reflectance or calibration drift. Improvement of surface reflectance including these calibration drifts or surface reflectance changes is required. The DT method used in AHI ESR and MODIS DT AOD retrievals results in a positive bias and higher AOD over East Asia compared to other products. The MISR AOD has smaller coverage than MODIS and VIIRS, but the AOD accuracy is higher than for the other products because of an improved surface-reflectance treatment that takes advantage of 

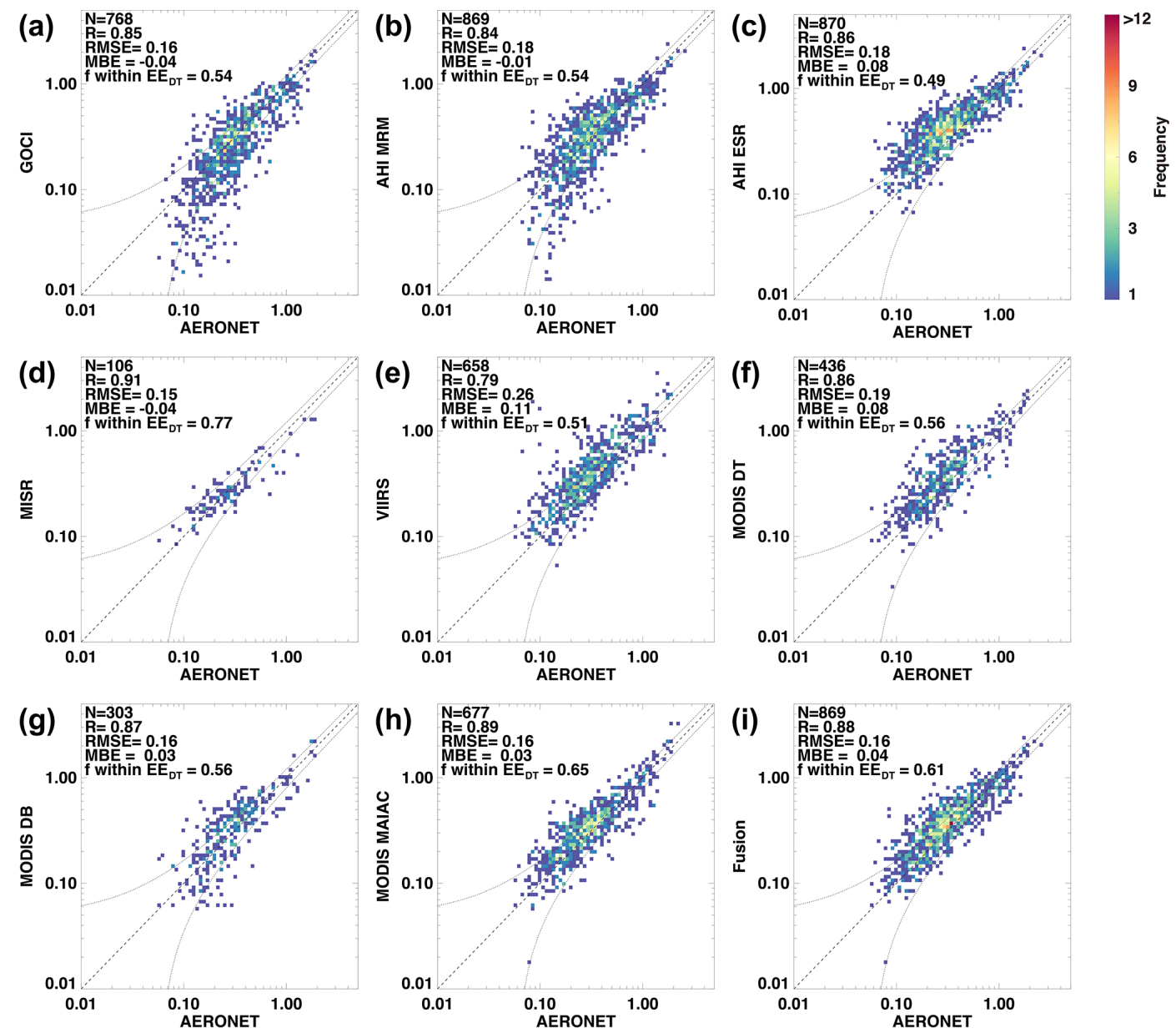

Figure 10. Validation of daily mean AOD using AERONET daily mean AOD during the KORUS-AQ campaign period (1 May to 12 June 2016) for the (a) GOCI, (b) AHI MRM, (c) AHI ESR, (d) MISR, (e) VIIRS, (f) MODIS DT10K, (g) MODIS DB, (h) MODIS MAIAC, and (h) fusion products. Lines indicate the one-to-one line (dashed) and the range of EE $E_{\mathrm{DT}}$ (dotted).

multi-angle measurements. However, it also seems that the MISR retrievals often screen out the highest AOD events, thereby biasing the sampling in this region. MISR uses neither SWIR channels nor pre-calculated surface reflectance; the algorithm does not retrieve AODs if aerosol signal is too high to get surface signals consistently. The range of MISR AOD product is set to be from 0.0 to 3.0 according to Witek et al. (2018). The maximum value is lower than others, such as 3.6 for GOCI and 5.0 for MODIS. These dynamic range and accuracy differences are due primarily to algorithm design, which is optimized for particular sensor specifications, such as the available channels, and are not related to orbit types. The MAIAC AOD shows high accuracy ( $f$ of 0.68 and 0.67 over land AERONET sites and SONET sites, respectively) during the campaign and best spatial coverage among MODIS products.

As GOCI and AHI AOD can be retrieved with high accuracy at near real time, the highly variable AOD conditions over East Asia, including transport from Russia to Japan, transport from China to South Korea, and local emissions in the SMA and subsequent transport to the Yellow Sea, can be successfully detected. This results in more representative daily AOD values. A combined AOD using GEO and LEO data is also tested using a median value selection at the daily scale with a $0.5^{\circ} \times 0.5^{\circ}$ grid resolution. The combined AOD has a more spatially continuous distribution and higher accuracy than the individual products do. Such a combined product reduces bias in aerosol measurements and will be of use in the evaluation of air quality models.

Although the validation using AERONET data reveal relative characteristics among the various AOD products in terms of accuracy, it is insufficient to thoroughly investigate these characteristics. Each algorithm includes subjective criteria, such as those used in cloud masking, surface-reflectance determination, aerosol model selection, inversion methods, and quality control. For example, the possible AOD range that can be retrieved and provided as the final AOD product varies among GOCI ( -0.05 to 3.6$)$, AHI ( -0.05 to 3.5 ), MODIS DT ( -1.0 to 5.0$)$, MODIS DB (0.0 to 5.0), MODIS MAIAC ( -0.1 to 5.0 ), and MISR (0.0 to 3.0). The quality flag is also 
(a) GOCI AOD - Fusion AOD

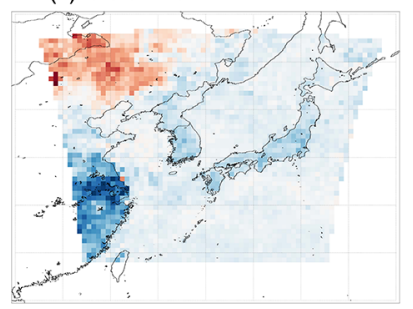

(e) VIIRS AOD - Fusion AOD (b) AHI MRM AOD - Fusion AOD

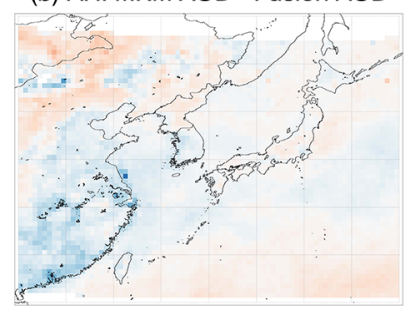

(f) MODIS DT AOD - Fusion AOD

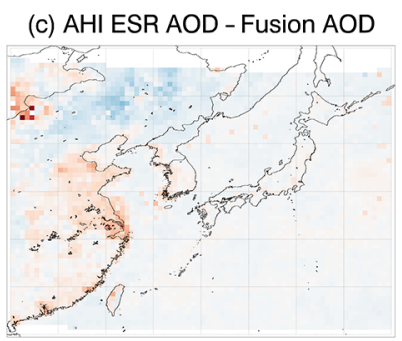

(g) MODIS DB AOD - Fusion AOD

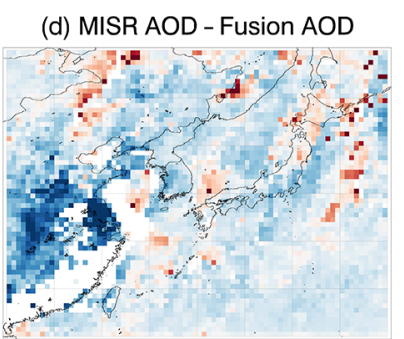

(h) MODIS MAIAC AOD - Fusion AOD
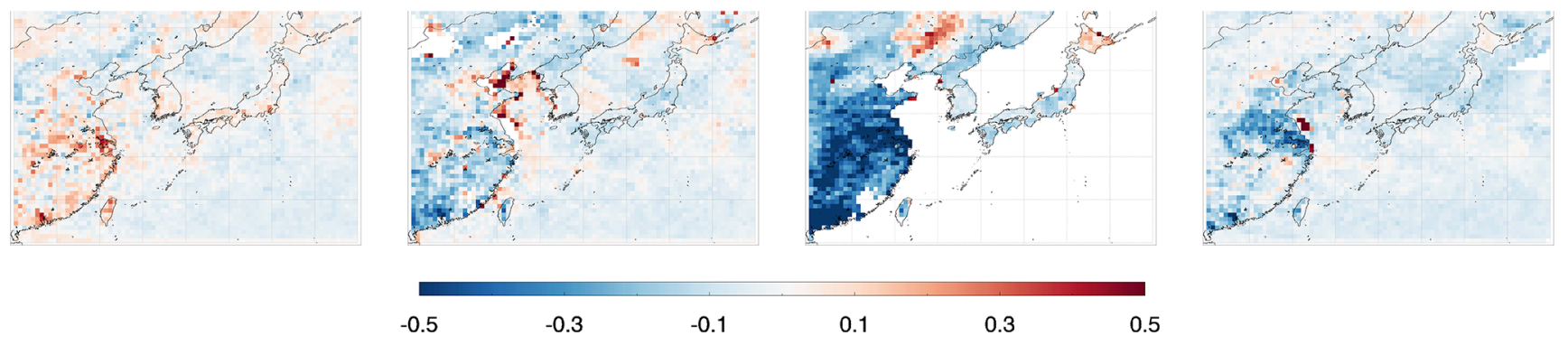

$-0.5$ $-0.3$ $-0.1$

Figure 11. Difference between campaign period mean gridded AOD of (a) GOCI, (b) AHI MRM, (c) AHI ESR, (d) MISR, (e) VIIRS,

Figure 11. Difference between campaign period mean gridded AOD of (a) GOCI, (b) AHI MRM, (c) AHI ESR, (d) MISR, (e) VIIRS, (f) MODIS DT10K, (g) MODIS DB, and (h) MODIS MAIAC and mean of fusion AOD during the KORUS-AQ campaign period (1 May to 12 June 2016).

determined subjectively. This results in differences in the identification of severe pollution events (e.g., AOD $>3.0$ or $>5.0$ ) among the various products. The target regions of the GEO and LEO measurements also differ. Aerosol retrieval algorithms for LEO measurements have been developed for global coverage, but those for GEO measurements only consider the accuracy within specific regions. Because the validation datasets differ, algorithm improvement proceeds differently among the various algorithms. Thus, the integration of multiple AOD products requires a comprehensive understanding of each product in the set. To reduce uncertainties arising from the use of different algorithms, the same algorithm can be applied to several sensors, just as the DB algorithm is applied to AVHRR, SeaWiFS, MODIS, and VIIRS measurements (Hsu et al., 2013; Lee et al., 2015; Sayer et al., 2012, 2017), and the DT algorithm is applied to MODIS, VIIRS, and planned to be applied to AHI and ABI. Additionally, LEO and GEO aerosol measurements can be integrated at the resolution of radiance data as L1B, not retrieved AOD products, as a concept of the multi-angle measurement. This integration will enable the retrieval of other aerosol optical properties, such as particle shape or absorptivity, which can be used to evaluate aerosol optical effects along with chemical composition.

This study focuses only on the spring season of 2016, when the KORUS-AQ campaign was conducted. An extended long-term study will be required to evaluate monthly or seasonal mean AOD trends of GEO and LEO measurements and combined AOD products. Additionally, the integration of multiple datasets may be improved by a con- sideration of pixel-level uncertainties; varying error characteristics, pixel size, and pixel shape; and the application of more advanced statistical techniques. Other optical properties, such as the Ångström exponent and single-scattering albedo, should also be investigated along with AOD in future studies.

Data availability. The GOCI and AHI Yonsei aerosol retrieval data during the KORUS-AQ campaign are available from https: //www-air.larc.nasa.gov/missions/korus-aq/ (NASA, 2019b). More periods of the GOCI and AHI Yonsei aerosol products are available through personal communication with the corresponding authors of the present paper. The AERONET and SONET data from during the KORUS-AQ campaign are available from https://aeronet.gsfc.nasa. gov (NASA, 2019a). The MODIS Dark Target, Deep Blue, MAIAC aerosol data, and MISR aerosol data are available from https: //earthdata.nasa.gov/ (NASA, 2019c). The VIIRS EPS aerosol data are available from one of authors of the present paper, Hongqing Liu (hongqing.liu@ noaa.gov), or from https://www.avl.class.noaa.gov/ (NOAA, 2019). The ECMWF atmospheric reanalyses data are available from https://cds.climate.copernicus.eu (ECMF, 2019).

Author contributions. MC, HyL, SL, JK, TE, BH, MG, EH, PS, HoL MC, and JK designed the data analysis. MC, HyL, SL, JK, $\mathrm{EH}$, and PS carried out the GOCI and AHI data production, distribution, and analysis. MC, HyL, SL, JK, TE, and BH carried out the installation, maintenance, and data analysis of the AERONET measurements during the 2016 KORUS-AQ campaign. MG provided the MISR AOD data and contributed to the data analysis. HoL pro- 
vided the VIIRS AOD data and contributed to the data analysis. MC and JK wrote the manuscript with comments from all coauthors.

Competing interests. The authors declare that they have no conflicts of interest.

Acknowledgements. We thank all principal investigators and their staff for establishing and maintaining the AERONET and SONET sites used in this investigation. We also thank the MODIS, MISR, and VIIRS science teams for providing valuable data for this research. This research was supported by the National Strategic Project-Fine Particle of the National Research Foundation of Korea (NRF) funded by the Ministry of Science and ICT (MSIT), the Ministry of Environment (ME), and the Ministry of Health and Welfare (MOHW; NRF-2017M3D8A1092021). Some research tasks were supported by the NASA ROSES-2013 Atmospheric Composition: Aura Science Team program and NASA Headquarter Directed Research and Technology Development Task (grant number: NNN13D455T, manager: Kenneth W. Jucks and Richard S. Eckman). A portion of this research was carried out at the Jet Propulsion Laboratory, California Institute of Technology, under a contract with the National Aeronautics and Space Administration. The editor and two anonymous reviewers are thanked for numerous useful comments, which improved the content and clarity of the manuscript.

Financial support. This research has been supported by the National Strategic Project-Fine Particle of the National Research Foundation of Korea (NRF) funded by the Ministry of Science and ICT (MSIT), the Ministry of Environment (ME), and the Ministry of Health and Welfare (MOHW) (grant no. NRF2017M3D8A1092021) and the NASA ROSES-2013 Atmospheric Composition: Aura Science Team program and NASA Headquarter Directed Research and Technology Development Task (grant no. NNN13D455T).

Review statement. This paper was edited by Cheng Liu and reviewed by two anonymous referees.

\section{References}

Copernicus Climate Change Service (C3S): ERA5: Fifth generation of ECMWF atmospheric reanalyses of the global climate, Copernicus Climate Change Service Climate Data Store (CDS), available at: https://cds.climate.copernicus.eu/cdsapp\#!/ home (last access: 29 July 2019), 2017.

Chen, X. F., Li, Z. Q., Zhao, S. S., Yang, L. K., Ma, Y., Liu, L., Li, D. H., Qie, L. L., and Xing, J.: Using the Gaofen-4 geostationary satellite to retrieve aerosols with high spatiotemporal resolution, J. Appl. Remote Sens., 12, 0426061-1-042606-18, https://doi.org/10.1117/1.JRS.12.042606, 2018.

Choi, M., Kim, J., Lee, J., Kim, M., Park, Y.-J., Jeong, U., Kim, W., Hong, H., Holben, B., Eck, T. F., Song, C. H., Lim, J.-H., and
Song, C.-K.: GOCI Yonsei Aerosol Retrieval (YAER) algorithm and validation during the DRAGON-NE Asia 2012 campaign, Atmos. Meas. Tech., 9, 1377-1398, https://doi.org/10.5194/amt9-1377-2016, 2016.

Choi, M., Kim, J., Lee, J., Kim, M., Park, Y.-J., Holben, B., Eck, T. F., Li, Z., and Song, C. H.: GOCI Yonsei aerosol retrieval version 2 products: an improved algorithm and error analysis with uncertainty estimation from 5-year validation over East Asia, Atmos. Meas. Tech., 11, 385-408, https://doi.org/10.5194/amt-11-3852018, 2018.

Cox, C. and Munk, W.: Statistics of the sea surface derived from sun glitter, J. Mar. Res., 13, 198-227, 1954.

Daisaku, U.: Aerosol Optical Depth product derived from Himawari-8 data for Asian dust monitoring, Meteorological Satellite Center Techinical Note, 61, 2016.

Diner, D. J., Beckert, J. C., Reilly, T. H., Bruegge, C. J., Conel, J. E., Kahn, R. A., Martonchik, J. V., Ackerman, T. P., Davies, R., Gerstl, S. A. W., Gordon, H. R., Muller, J. P., Myneni, R. B., Sellers, P. J., Pinty, B., and Verstraete, M. M.: Multi-angle Imaging SpectroRadiometer (MISR) - Instrument description and experiment overview, IEEE T. Geosci. Remote, 36, 1072-1087, 1998.

Eck, T. F., Holben, B. N., Reid, J. S., Dubovik, O., Smirnov, A., O'Neill, N. T., Slutsker, I., and Kinne, S.: Wavelength dependence of the optical depth of biomass burning, urban, and desert dust aerosols, J. Geophys. Res.-Atmos., 104, 3133331349, 1999.

Eck, T. F., Holben, B. N., Reid, J. S., Xian, P., Giles, D. M., Sinyuk, A., Smirnov, A., Schafer, J. S., Slutsker, I., Kim, J., Koo, J. H., Choi, M., Kim, K. C., Sano, I., Arola, A., Sayer, A. M., Levy, R. C., Munchak, L. A., O’Neill, N. T., Lyapustin, A., Hsu, N. C., Randles, C. A., Da Silva, A. M., Buchard, V., Govindaraju, R. C., Hyer, E., Crawford, J. H., and Wang, P. Xia, X.: Observations of the Interaction and Transport of Fine Mode Aerosols With Cloud and/or Fog in Northeast Asia From Aerosol Robotic Network and Satellite Remote Sensing, J. Geophys. Res.-Atmos., 123, 55605587, 2018.

ECMWF: Copernicus Climate Data Store, available at: https://cds. climate.copernicus.eu, last access: 29 July 2019.

Gao, M., Guttikunda, S. K., Carmichael, G. R., Wang, Y. S., Liu, Z. R., Stanier, C. O., Saide, P. E., and Yu, M.: Health impacts and economic losses assessment of the 2013 severe haze event in Beijing area, Sci. Total Environ., 511, 553-561, 2015.

Garay, M. J., Kalashnikova, O. V., and Bull, M. A.: Development and assessment of a higher-spatial-resolution $(4.4 \mathrm{~km})$ MISR aerosol optical depth product using AERONETDRAGON data, Atmos. Chem. Phys., 17, 5095-5106, https://doi.org/10.5194/acp-17-5095-2017, 2017.

GCOS: The global observing system for climate: Implementation needs, Geneva, Switzerland, 2016.

Giles, D. M., Sinyuk, A., Sorokin, M. G., Schafer, J. S., Smirnov, A., Slutsker, I., Eck, T. F., Holben, B. N., Lewis, J. R., Campbell, J. R., Welton, E. J., Korkin, S. V., and Lyapustin, A. I.: Advancements in the Aerosol Robotic Network (AERONET) Version 3 database - automated near-real-time quality control algorithm with improved cloud screening for Sun photometer aerosol optical depth (AOD) measurements, Atmos. Meas. Tech., 12, 169209, https://doi.org/10.5194/amt-12-169-2019, 2019.

Goto, D., Kikuchi, M., Suzuki, K., Hayasaki, M., Yoshida, M., Nagao, T. M., Choi, M., Kim, J., Sugimoto, N., Shimizu, A., 
Oikawa, E., and Nakajima, T.: Aerosol model evaluation using two geostationary satellites over East Asia in May 2016, Atmos. Res., 217, 93-113, 2019.

Gupta, P., Levy, R. C., Mattoo, S., Remer, L. A., and Munchak, L. A.: A surface reflectance scheme for retrieving aerosol optical depth over urban surfaces in MODIS Dark Target retrieval algorithm, Atmos. Meas. Tech., 9, 3293-3308, https://doi.org/10.5194/amt-9-3293-2016, 2016.

Herman, J. R. and Celarier, E. A.: Earth surface reflectivity climatology at 340-380 nm from TOMS data, J. Geophys. Res.Atmos., 102, 28003-28011, 1997.

Higurashi, A. and Nakajima, T.: Development of a two-channel aerosol retrieval algorithm on a global scale using NOAA AVHRR, J. Atmos. Sci., 56, 924-941, 1999.

Holben, B. N., Eck, T. F., Slutsker, I., Tanre, D., Buis, J. P., Setzer, A., Vermote, E., Reagan, J. A., Kaufman, Y. J., Nakajima, T., Lavenu, F., Jankowiak, I., and Smirnov, A.: AERONET - A federated instrument network and data archive for aerosol characterization, Remote Sens. Environ., 66, 1-16, 1998.

Holben, B. N., Kim, J., Sano, I., Mukai, S., Eck, T. F., Giles, D. M., Schafer, J. S., Sinyuk, A., Slutsker, I., Smirnov, A., Sorokin, M., Anderson, B. E., Che, H., Choi, M., Crawford, J. H., Ferrare, R. A., Garay, M. J., Jeong, U., Kim, M., Kim, W., Knox, N., Li, Z., Lim, H. S., Liu, Y., Maring, H., Nakata, M., Pickering, K. E., Piketh, S., Redemann, J., Reid, J. S., Salinas, S., Seo, S., Tan, F., Tripathi, S. N., Toon, O. B., and Xiao, Q.: An overview of mesoscale aerosol processes, comparisons, and validation studies from DRAGON networks, Atmos. Chem. Phys., 18, 655-671, https://doi.org/10.5194/acp-18-655-2018, 2018.

Hsu, N. C., Tsay, S. C., King, M. D., and Herman, J. R.: Aerosol properties over bright-reflecting source regions, IEEE T. Geosci. Remote, 42, 557-569, 2004.

Hsu, N. C., Jeong, M. J., Bettenhausen, C., Sayer, A. M., Hansell, R., Seftor, C. S., Huang, J., and Tsay, S. C.: Enhanced Deep Blue aerosol retrieval algorithm: The second generation, J. Geophys. Res.-Atmos., 118, 9296-9315, 2013.

Huang, J. F., Kondragunta, S., Laszlo, I., Liu, H. Q., Remer, L. A., Zhang, H., Superczynski, S., Ciren, P., Holben, B. N., and Petrenko, M.: Validation and expected error estimation of SuomiNPP VIIRS aerosol optical thickness and Angstrom exponent with AERONET, J. Geophys. Res.-Atmos., 121, 7139-7160, 2016.

Hyer, E. J., Reid, J. S., and Zhang, J.: An over-land aerosol optical depth data set for data assimilation by filtering, correction, and aggregation of MODIS Collection 5 optical depth retrievals, Atmos. Meas. Tech., 4, 379-408, https://doi.org/10.5194/amt-4379-2011, 2011.

Ingmann, P., Veihelmann, B., Langen, J., Lamarre, D., Stark, H., and Courrèges-Lacoste, G. B.: Requirements for the GMES Atmosphere Service and ESA's implementation concept: Sentinels4/-5 and -5p, Remote Sens. Environ., 120, 58-69, 2012.

IPCC: Climate Change 2013: The Physical Science Basis. Contribution of Working Group I to the Fifth Assessment Report of the Intergovernmental Panel on Climate Change, Cambridge University Press, Cambridge, United Kingdom and New York, NY, USA, 2013.

Iwabuchi, H., Yamada, S., Katagiri, S., Yang, P., and Okamoto, H.: Radiative and Microphysical Properties of Cirrus Cloud Inferred from Infrared Measurements Made by the Moderate Resolution
Imaging Spectroradiometer (MODIS). Part I: Retrieval Method, J. Appl. Meteorol. Clim., 53, 1297-1316, 2014.

Jackson, J. M., Liu, H. Q., Laszlo, I., Kondragunta, S., Remer, L. A., Huang, J. F., and Huang, H. C.: Suomi-NPP VIIRS aerosol algorithms and data products, J. Geophys. Res.-Atmos., 118, 12673 12689, 2013.

Jacob, D. J., Crawford, J. H., Kleb, M. M., Connors, V. S., Bendura, R. J., Raper, J. L., Sachse, G. W., Gille, J. C., Emmons, L., and Heald, C. L.: Transport and Chemical Evolution over the Pacific (TRACE-P) aircraft mission: Design, execution, and first results, J. Geophys. Res.-Atmos., 108, 9000, https://doi.org/10.1029/2002JD003276, 2003.

Jeon, W., Choi, Y., Percell, P., Souri, A. H., Song, C.-K., Kim, S.T., and Kim, J.: Computationally efficient air quality forecasting tool: implementation of STOPS v1.5 model into CMAQ v5.0.2 for a prediction of Asian dust, Geosci. Model Dev., 9, 36713684, https://doi.org/10.5194/gmd-9-3671-2016, 2016.

Jeong, U., Kim, J., Ahn, C., Torres, O., Liu, X., Bhartia, P. K., Spurr, R. J. D., Haffner, D., Chance, K., and Holben, B. N.: An optimal-estimation-based aerosol retrieval algorithm using OMI near-UV observations, Atmos. Chem. Phys., 16, 177-193, https://doi.org/10.5194/acp-16-177-2016, 2016.

Jiang, T., Chen, B., Chan, K. K. Y., and Xu, B.: Himawari8/AHI and MODIS Aerosol Optical Depths in China: Evaluation and Comparison, Remote Sens.-Basel, 11, 1011, https://doi.org/10.3390/rs11091011, 2019.

Kaufman, Y. J., Tanre, D., Remer, L. A., Vermote, E. F., Chu, A., and Holben, B. N.: Operational remote sensing of tropospheric aerosol over land from EOS moderate resolution imaging spectroradiometer, J. Geophys. Res.-Atmos., 102, 17051-17067, 1997.

Kikuchi, M., Murakami, H., Suzuki, K., Nagao, T. M., and Higurashi, A.: Improved Hourly Estimates of Aerosol Optical Thickness Using Spatiotemporal Variability Derived From Himawari8 Geostationary Satellite, IEEE T. Geosci. Remote, 56, 34423455, 2018.

Kim, J., Lee, J., Lee, H. C., Higurashi, A., Takemura, T., and Song, C. H.: Consistency of the aerosol type classification from satellite remote sensing during the Atmospheric Brown Cloud-East Asia Regional Experiment campaign, J. Geophys. Res.-Atmos., 112, D22S33, https://doi.org/10.1029/2006JD008201, 2007.

Kim, J., Yoon, J. M., Ahn, M. H., Sohn, B. J., and Lim, H. S.: Retrieving aerosol optical depth using visible and mid-IR channels from geostationary satellite MTSAT-1R, Int. J. Remote Sens., 29, 6181-6192, 2008.

Kim, J., U. Jeong, M. Ahn, J.H. Kim, R.J. Park, H. Lee, C.H. Song, Y. Choi, K. Lee, J. Yoo, M. Jeong, S.K. Park, K. Lee, C. Song, S. Kim, Y. Kim, S. Kim, M. Kim, S. Go, X. Liu, K. Chance, C. Chan Miller, J. Al-Saadi, B. Veihelmann, P.K. Bhartia, O. Torres, G.G. Abad, D.P. Haffner, D.H. Ko, S.H. Lee, J. Woo, H. Chong, S.S. Park, D. Nicks, W.J. Choi, K. Moon, A. Cho, J. Yoon, S. Kim, H. Hong, K. Lee, H. Lee, S. Lee, M. Choi, P. Veefkind, P. Levelt, D.P. Edwards, M. Kang, M. Eo, J. Bak, K. Baek, H Kwon, J. Yang, J. Park, K.M. Han, B. Kim, H. Shin, H. Choi, E. Lee, J. Chong, Y. Cha, J. Koo, H. Irie, S. Hayashida, Y. Kasai, Y. Kanaya, C. Liu, J. Lin, J.H. Crawford, G.R. Carmichael, M.J. Newchurch, B.L. Lefer, J.R. Herman, R.J. Swap, A.K. Lau, T.P. Kurosu, G. Jaross, B. Ahlers, M. Dobber, C. McElroy, and Y. Choi: New Era of Air Quality Monitoring from Space: 
Geostationary Environment Monitoring Spectrometer (GEMS), B. Am. Meteorol. Soc., https://doi.org/10.1175/BAMS-D-180013.1, 2019.00, 2019.

Kim, M., Kim, J., Wong, M. S., Yoon, J., Lee, J., Wu, D., Chan, P. W., Nichol, J. E., Chung, C. Y., and Ou, M. L.: Improvement of aerosol optical depth retrieval over Hong Kong from a geostationary meteorological satellite using critical reflectance with background optical depth correction, Remote Sens. Environ., 142, 176-187, 2014.

Kim, M., Kim, J., Jeong, U., Kim, W., Hong, H., Holben, B., Eck, T. F., Lim, J. H., Song, C. K., Lee, S., and Chung, C.-Y.: Aerosol optical properties derived from the DRAGON-NE Asia campaign, and implications for a single-channel algorithm to retrieve aerosol optical depth in spring from Meteorological Imager (MI) on-board the Communication, Ocean, and Meteorological Satellite (COMS), Atmos. Chem. Phys., 16, 1789-1808, https://doi.org/10.5194/acp-16-1789-2016, 2016.

Kim, S. W., Yoon, S. C., Kim, J., and Kim, S. Y.: Seasonal and monthly variations of columnar aerosol optical properties over east Asia determined from multi-year MODIS, LIDAR, and AERONET Sun/sky radiometer measurements, Atmos. Environ., 41, 1634-1651, 2007.

Kim, Y. P., Lee, G., Emmons, L., Park, R., and Lin, N. H.: Preface to a Special Issue "Megacity Air Pollution Studies (MAPS)", Aerosol Air Qual. Res., 18, I-IV, https://doi.org/10.4209/aaqr.2018.09.maps, 2018.

Knapp, K. R., Vonder Haar, T. H., and Kaufman, Y. J.: Aerosol optical depth retrieval from GOES-8: Uncertainty study and retrieval validation over South America, J. Geophys. Res.-Atmos., 107, 4055, https://doi.org/10.1029/2001JD000505, 2002.

Koelemeijer, R. B. A., de Haan, J. F., and Stammes, P.: A database of spectral surface reflectivity in the range $335-772 \mathrm{~nm}$ derived from 5.5 years of GOME observations, J. Geophys. Res.-Atmos., 108, 4070, https://doi.org/10.1029/2002JD002429, 2003.

Laszlo, I. and Liu, H.: EPS Aerosol Optical Depth (AOD) Algorithm Theoretical Basis Document, NOAA NESDIS Center for Satellite Applications and Research, 2016.

Lee, J., Kim, J., Song, C. H., Ryu, J. H., Ahn, Y. H., and Song, C. K.: Algorithm for retrieval of aerosol optical properties over the ocean from the Geostationary Ocean Color Imager, Remote Sens. Environ., 114, 1077-1088, 2010.

Lee, J., Hsu, N. C., Bettenhausen, C., Sayer, A. M., Seftor, C. J., and Jeong, M. J.: Retrieving the height of smoke and dust aerosols by synergistic use of VIIRS, OMPS, and CALIOP observations, J. Geophys. Res.-Atmos., 120, 8372-8388, 2015.

Lee, S., Song, C. H., Park, R. S., Park, M. E., Han, K. M., Kim, J., Choi, M., Ghim, Y. S., and Woo, J.-H.: GIST-PM-Asia v1: development of a numerical system to improve particulate matter forecasts in South Korea using geostationary satellite-retrieved aerosol optical data over Northeast Asia, Geosci. Model Dev., 9, 17-39, https://doi.org/10.5194/gmd-9-17-2016, 2016.

Lee, S., Hong, J., Cho, Y., Choi, M., Kim, J., Park, S. S., Ahn, J. Y., Kim, S. K., Moon, K. J., Eck, T. F., Holben, B. N., and Koo, J. H.: Characteristics of Classified Aerosol Types in South Korea during the MAPS-Seoul Campaign, Aerosol Air Qual. Res., 18, 2195-2206, 2018.

Lee, S., Kim, J., Choi, M., Hong, J., Lim, H., Eck, T. F., Holben, B. N., Ahn, J.-Y., Kim, J., and Koo, J.-H.: Analysis of long-range transboundary transport (LRTT) effect on Korean aerosol pol- lution during the KORUS-AQ campaign, Atmos. Environ., 204, 53-67, 2019.

Lennartson, E. M., Wang, J., Gu, J., Castro Garcia, L., Ge, C., Gao, M., Choi, M., Saide, P. E., Carmichael, G. R., Kim, J., and Janz, S. J.: Diurnal variation of aerosol optical depth and PM2.5 in South Korea: a synthesis from AERONET, satellite (GOCI), KORUS-AQ observation, and the WRF-Chem model, Atmos. Chem. Phys., 18, 15125-15144, https://doi.org/10.5194/acp-1815125-2018, 2018.

Levy, R. C., Remer, L. A., Mattoo, S., Vermote, E. F., and Kaufman, Y. J.: Second-generation operational algorithm: Retrieval of aerosol properties over land from in version of Moderate Resolution Imaging Spectroradiometer spectral reflectance, J. Geophys. Res.-Atmos., 112, D13211, https://doi.org/10.1029/2006JD007815, 2007.

Levy, R. C., Mattoo, S., Munchak, L. A., Remer, L. A., Sayer, A. M., Patadia, F., and Hsu, N. C.: The Collection 6 MODIS aerosol products over land and ocean, Atmos. Meas. Tech., 6, 29893034, https://doi.org/10.5194/amt-6-2989-2013, 2013.

Levy, R. C., Mattoo, S., Sawyer, V., Shi, Y., Colarco, P. R., Lyapustin, A. I., Wang, Y., and Remer, L. A.: Exploring systematic offsets between aerosol products from the two MODIS sensors, Atmos. Meas. Tech., 11, 4073-4092, https://doi.org/10.5194/amt-11-4073-2018, 2018.

Li, Z. Q., H. Xu Li, K. T., Li, D. H., Xie, Y. S., Li, L., Zhang, Y., Gu, X. F., Zhao, W., Tian, Q. J., Deng, R. R., Su, X. L., Huang, B., Qiao, Y. L., Cui, W. Y., Hu, Y., Gong, C. L., Wang, Y. Q., Wang, X. F., Wang, J. P., Du, W. B., Pan, Z. Q., Li, Z. Z., and $\mathrm{Bu}, \mathrm{D}$.: Comprehensive study of optical, physical, chemical, and radiative properties of total columnar atmospheric aerosols over China: an overview of Sun-Sky Radiometer Observation Network (SONET) measurements, B. Am. Meteorol. Soc., 99, 739755, 2018.

Lim, H., Choi, M., Kim, J., Kasai, Y., and Chan, P.: AHI/Himawari8 Yonsei Aerosol Retrieval (YAER): Algorithm, Validation and Merged Products, Remote Sens.-Basel, 10, 699, https://doi.org/10.3390/rs10050699, 2018.

Lim, S. S., Vos, T., Flaxman, A. D., Danaei, G., Shibuya, K., Adair-Rohani, H., Amann, M., Anderson, H. R., Andrews, K. G., Aryee, M., Atkinson, C., Bacchus, L. J., Bahalim, A. N., Balakrishnan, K., Balmes, J., Barker-Collo, S., Baxter, A., Bell, M. L., Blore, J. D., Blyth, F., Bonner, C., Borges, G., Bourne, R., Boussinesq, M., Brauer, M., Brooks, P., Bruce, N. G., Brunekreef, B., Bryan-Hancock, C., et al.: A comparative risk assessment of burden of disease and injury attributable to 67 risk factors and risk factor clusters in 21 regions, 1990-2010: a systematic analysis for the Global Burden of Disease Study 2010, Lancet, 380, 2224-2260, 2012.

Lyapustin, A., Martonchik, J., Wang, Y. J., Laszlo, I., and Korkin, S.: Multiangle implementation of atmospheric correction (MAIAC): 1. Radiative transfer basis and look-up tables, J. Geophys. Res.-Atmos., 116, D03210, https://doi.org/10.1029/2010jd014985, 2011a.

Lyapustin, A., Wang, Y., Laszlo, I., Kahn, R., Korkin, S., Remer, L., Levy, R., and Reid, J. S.: Multiangle implementation of atmospheric correction (MAIAC): 2. Aerosol algorithm, J. Geophys. Res.-Atmos., 116, D03211, https://doi.org/10.1029/2010jd014986, 2011b. 
Lyapustin, A., Wang, Y., Korkin, S., and Huang, D.: MODIS Collection 6 MAIAC algorithm, Atmos. Meas. Tech., 11, 5741-5765, https://doi.org/10.5194/amt-11-5741-2018, 2018.

Mehta, M., Singh, R., Singh, A., Singh, N., and Anshumali: Recent global aerosol optical depth variations and trends - A comparative study using MODIS and MISR level 3 datasets, Remote Sens. Environ., 181, 137-150, 2016.

Munchak, L. A., Levy, R. C., Mattoo, S., Remer, L. A., Holben, B. N., Schafer, J. S., Hostetler, C. A., and Ferrare, R. A.: MODIS $3 \mathrm{~km}$ aerosol product: applications over land in an urban/suburban region, Atmos. Meas. Tech., 6, 1747-1759, https://doi.org/10.5194/amt-6-1747-2013, 2013.

NASA: AERONET homepage, available at: https://aeronet.gsfc. nasa.go, last access: 29 July 2019a.

NASA : KORUS-AQ homepage, available at: https://www-air.larc. nasa.gov/missions/korus-aq/ last access: 29 July 2019 b.

NASA: Earthdata homepage, available at: https://earthdata.nasa. gov, last access: 29 July 2019c.

Nakajima, T., Yoon, S. C., Ramanathan, V., Shi, G. Y., Takemura, T., Higurashi, A., Takamura, T., Aoki, K., Sohn, B. J., Kim, S. W., Tsuruta, H., Sugimoto, N., Shimizu, A., Tanimoto, H., Sawa, Y., Lin, N. H., Lee, C. T., Goto, D., and Schutgens, N.: Overview of the Atmospheric Brown Cloud East Asian Regional Experiment 2005 and a study of the aerosol direct radiative forcing in east Asia, J. Geophys. Res.-Atmos., 112, DS4S91, https://doi.org/10.1029/2007JD009009, 2007.

NOAA: NOAA Comprehensive Large Array-Data Stewardship System (CLARSS), available at: https://www.avl.class.noaa.gov, last access: 29 July 2019.

Pang, J. M., Liu, Z. Q., Wang, X. M., Bresch, J., Ban, J. M., Cnen, D., and Kim, J.: Assimilating AOD retrievals from GOCI and VIIRS to forecast surface PM2.5 episodes over Eastern China, Atmos. Environ., 179, 288-304, 2018.

Park, M. E., Song, C. H., Park, R. S., Lee, J., Kim, J., Lee, S., Woo, J.-H., Carmichael, G. R., Eck, T. F., Holben, B. N., Lee, S.-S., Song, C. K., and Hong, Y. D.: New approach to monitor transboundary particulate pollution over Northeast Asia, Atmos. Chem. Phys., 14, 659-674, https://doi.org/10.5194/acp-14-6592014, 2014.

Park, S., Shin, M., Im, J., Song, C.-K., Choi, M., Kim, J., Lee, S., Park, R., Kim, J., Lee, D.-W., and Kim, S.-K.: Estimation of ground-level particulate matter concentrations through the synergistic use of satellite observations and process-based models over South Korea, Atmos. Chem. Phys., 19, 1097-1113, https://doi.org/10.5194/acp-19-1097-2019, 2019.

Remer, L. A., Kaufman, Y. J., Tanré, D., Mattoo, S., Chu, D. A., Martins, J. V., Li, R. R., Ichoku, C., Levy, R. C., Kleidman, R. G., Eck, T. F., Vermote, E., and Holben, B. N.: The MODIS Aerosol Algorithm, Products, and Validation, J. Atmos. Sci., 62, 947-973, 2005.

Saide, P. E., Kim, J., Song, C. H., Choi, M., Cheng, Y. F., and Carmichael, G. R.: Assimilation of next generation geostationary aerosol optical depth retrievals to improve air quality simulations, Geophys. Res. Lett., 41, 9188-9196, 2014.

Sayer, A. M., Hsu, N. C., Bettenhausen, C., Ahmad, Z., Holben, B. N., Smirnov, A., Thomas, G. E., and Zhang, J.: SeaWiFS Ocean Aerosol Retrieval (SOAR): Algorithm, validation, and comparison with other data sets, J. Geophys. Res.-Atmos., 117, D03206, https://doi.org/10.1029/2011JD016689, 2012.
Sayer, A. M., Hsu, N. C., Bettenhausen, C., and Jeong, M. J.: Validation and uncertainty estimates for MODIS Collection 6 "Deep Blue" aerosol data, J. Geophys. Res.-Atmos., 118, 7864-7872, 2013.

Sayer, A. M., Munchak, L. A., Hsu, N. C., Levy, R. C., Bettenhausen, C., and Jeong, M. J.: MODIS Collection 6 aerosol products: Comparison between Aqua's e-Deep Blue, Dark Target, and "merged" data sets, and usage recommendations, J. Geophys. Res.-Atmos., 119, 13965-13989, 2014.

Sayer, A. M., Hsu, N. C., Lee, J., Carletta, N., Chen, S.-H., and Smirnov, A.: Evaluation of NASA Deep Blue/SOAR aerosol retrieval algorithms applied to AVHRR measurements, J. Geophys. Res.-Atmos., 122, 9945-9967, 2017.

Sayer, A. M., Hsu, N. C., Lee, J., Kim, W. V., and Dutcher, S. T.: Validation, Stability, and Consistency of MODIS Collection 6.1 and VIIRS Version 1 Deep Blue Aerosol Data Over Land, J. Geophys. Res.-Atmos., 124, 4658-4688, 2019.

Torres, O., Bhartia, P. K., Herman, J. R., Ahmad, Z., and Gleason, J.: Derivation of aerosol properties from satellite measurements of backscattered ultraviolet radiation: Theoretical basis, J. Geophys. Res.-Atmos., 103, 17099-17110, 1998.

Urm, Y.-D. and Sohn, B.-J.: Estimation of aerosol optical thickness over east asia using GMS-5 visible channel measurements, J. Atmos., 15, 203-211, 2005.

Wang, J., Christopher, S. A., Brechtel, F., Kim, J., Schmid, B., Redemann, J., Russell, P. B., Quinn, P., and Holben, B. N.: Geostationary satellite retrievals of aerosol optical thickness during ACE-Asia, J. Geophys. Res.-Atmos., 108, 8657, https://doi.org/10.1029/2003jd003580, 2003.

Witek, M. L., Garay, M. J., Diner, D. J., Bull, M. A., and Seidel, F. C.: New approach to the retrieval of AOD and its uncertainty from MISR observations over dark water, Atmos. Meas. Tech., 11, 429-439, https://doi.org/10.5194/amt-11-429-2018, 2018.

Xiao, Q., Zhang, H., Choi, M., Li, S., Kondragunta, S., Kim, J., Holben, B., Levy, R. C., and Liu, Y.: Evaluation of VIIRS, GOCI, and MODIS Collection 6 AOD retrievals against ground sunphotometer observations over East Asia, Atmos. Chem. Phys., 16, 1255-1269, https://doi.org/10.5194/acp-16-1255-2016, 2016.

Yoon, J., Burrows, J. P., Vountas, M., von Hoyningen-Huene, W., Chang, D. Y., Richter, A., and Hilboll, A.: Changes in atmospheric aerosol loading retrieved from space-based measurements during the past decade, Atmos. Chem. Phys., 14, 68816902, https://doi.org/10.5194/acp-14-6881-2014, 2014.

Yoon, J. M., Kim, J., Lee, J. H., Cho, H. K., Sohn, B. J., and Ahn, M. H.: Retrieval of Aerosol Optical Depth over East Asia from a Geostationary Satellite, MTSAT-1R, Asia-Pac J. Atmos. Sci., 43, 133-142, 2007.

Zhang, H., Kondragunta, S., Laszlo, I., Liu, H., Remer, L. A., Huang, J., Superczynski, S., and Ciren, P.: An enhanced VIIRS aerosol optical thickness (AOT) retrieval algorithm over land using a global surface reflectance ratio database, J. Geophys. Res.Atmos., 121, 10717-710738, 2016.

Zhang, J. L. and Reid, J. S.: MODIS aerosol product analysis for data assimilation: Assessment of over-ocean level 2 aerosol optical thickness retrievals, J. Geophys. Res.-Atmos., 111, D22207, https://doi.org/10.1029/2005JD006898, 2006.

Zhang, W. H., Xu, H., and Zheng, F. J.: Aerosol Optical Depth Retrieval over East Asia Using Himawari-8/AHI Data, Remote Sens.-Basel, 10, 137, https://doi.org/10.3390/rs10010137, 2018. 
Zhao, B., Jiang, J. H., Gu, Y., Diner, D., Worden, J., Liou, K. N., Su, H., Xing, J., Garay, M., and Huang, L.: Decadalscale trends in regional aerosol particle properties and their linkage to emission changes, Environ. Res. Lett., 12, 054021, https://doi.org/10.1088/1748-9326/aa6cb2, 2017.

Zoogman, P., Liu, X., Suleiman, R. M., Pennington, W. F., Flittner, D. E., Al-Saadi, J. A., Hilton, B. B., Nicks, D. K., Newchurch, M. J., Carr, J. L., Janz, S. J., Andraschko, M. R., Arola, A., Baker, B. D., Canova, B. P., Chan Miller, C., Cohen, R. C., Davis, J. E., Dussault, M. E., Edwards, D. P., Fishman, J., Ghulam, A., González Abad, G., Grutter, M., Herman, J. R., Houck, J., Jacob, D. J., Joiner, J., Kerridge, B. J., Kim, J., Krotkov, N. A., Lamsal, L., Li, C., Lindfors, A., Martin, R. V., McElroy, C. T., McLinden, C., Natraj, V., Neil, D. O., Nowlan, C. R., O’Sullivan, E. J., Palmer, P. I., Pierce, R. B., Pippin, M. R., Saiz-Lopez, A., Spurr, R. J. D., Szykman, J. J., Torres, O., Veefkind, J. P., Veihelmann, B., Wang, H., Wang, J., and Chance, K.: Tropospheric emissions: Monitoring of pollution (TEMPO), J. Quant. Spectrosc. Ra., 186, 17-39, 2017. 